\title{
Illuminating the 'Face' of Justice: A Meta-Analytic Examination of Leadership and Organizational Justice
}

\section{Elizabeth P. Karam, Jinyu Hu, Robert B. Davison, Matthew Juravich, Jennifer D. Nahrgang, Stephen E. Humphrey and D. Scott DeRue}

Texas Tech University; University of Nevada, Reno; University of Kansas; The University of Akron; Arizona State University; Pennsylvania State University; University of Michigan

ABSTRACT A significant body of research has described effective leader behaviours and has connected these behaviours to positive employee outcomes. However, this research has yet to be systematically integrated with organizational justice research to describe how leader behaviours inform justice perceptions. Therefore, we conduct a meta-analysis $(k=166$, $\mathcal{N}=46,034)$ to investigate how three types of leader behaviours (task, relational, and change) inform four dimensions of organizational justice (procedural, distributive, interpersonal, and informational) referenced to the leader and to the organization. Further, we examine the joint impact of leader behaviours and justice perceptions on social exchange quality (i.e., leadermember exchange), task performance, and job satisfaction. Our results suggest that leader behaviours differentially inform leader- and organization-focused justice perceptions, and the joint effect of leader behaviours and justice perceptions offer more nuanced explanations for outcomes.

Keywords: Leader behaviours, organizational justice, meta-analysis, social exchange theory

\section{INTRODUCTION}

Leadership is one of the most studied phenomenon in management (Cascio and Aguinis, 2008), and an extensive body of research has examined the behaviours that contribute to effective leadership (Dinh et al., 2014). For example, studies that have examined task leader behaviours (i.e., transactional leadership, contingent reward, initiating structure) have articulated that effective leaders define roles, solve problems, and plan Lubbock, TX 79409-2101 (elizabeth.karam@ttu.edu). 
activities (Bass, 1985; Burns, 1978; Podsakoff et al., 2006; Yukl, 2012). Research into relational leader behaviours (e.g., consideration, servant leadership, participative leadership) describe how leaders demonstrate support and develop followers (Fleishman, 1953; Greenleaf, 1977; Spreitzer, 2007; Yukl, 2012). Change leadership research (e.g., transformational, charismatic) has focused on how effective leaders inspire, develop a vision, and encourage innovation (Bass, 1985; Howell and Avolio, 1993; Yukl, 2012). The positive effects of leaders on employee attitudes and behaviours have been noted in numerous conceptual and meta-analytic reviews (e.g., DeRue et al., 2011; Gardner et al., 2010; Judge et al., 2004). Indeed, this body of research contains detailed descriptions of what leaders do and how they affect individual, team, and organizational performance outcomes.

A significant stream of organizational justice research has also examined the role of the leader in employee assessments of (un)fair treatment (Colquitt et al., 2013; Rupp and Cropanzano, 2002; Rupp et al., 2014). This research has found that justice perceptions of the leader (i.e., supervisor- or leader-focused justice), rather than perceptions of other organizational entities (e.g., the organization itself), are most strongly related to employee outcomes (Colquitt et al., 2013; Rupp et al., 2014). This is not surprising given that an employee's relationship with his or her leader 'may be the single most powerful connection an employee can build in an organization' (Hui et al., 2004, p. 233). Therefore, justice research has identified the leader as an important source of justice (thereby answering the question, who is responsible for the (un)just treatment?), yet this research has not adequately answered the question of what behaviours the leader engages in to inform justice perceptions. This has prompted Rupp and Aquino (2009) to suggest that justice research is 'ripe for integrative application' with other theories so that more specific guidance can be given to leaders about how to promote fairness in the workplace (p. 208). Hence, one purpose of this study is to integrate research on leader behaviours with organizational justice research to explicate the specific behaviours that leaders utilize to inform justice perceptions. In doing so, we attempt to provide greater focus to the 'face' (i.e., the leader) of justice.

An increased understanding of the relationships between leader behaviours and justice perceptions is important for two reasons. First, employee-leader relationships are often characterized as social exchange relationships and are distinguished from other forms of exchanges by having expectations of longer-term, interdependent interactions that generate trust, reciprocal behaviours, and high-quality relationships (Blau, 1964; Cropanzano and Mitchell, 2005; Mitchell et al., 2012). This dynamic, interactive relationship suggests that employees' justice perceptions may not be based exclusively on the leader's justice decisions, but that these perceptions may also be informed by a range of the leader's role-relevant behaviours. For this reason, examining only leader-focused justice perceptions, particularly in relation to an explicit 'event' (e.g., a single episode such as a performance appraisal), fails to consider the broader task, relational, and change interactions between the leader and the employee and how these interactions may impact justice assessments.

Second, studies that examine leader-focused justice commonly focus on research questions related to either (a) investigating the unique effects of leader-focused justice 
dimensions (i.e., procedural, distributive, interpersonal, informational justice) on organizational outcomes (e.g., Colquitt et al., 2013; Frazier et al., 2010), or (b) exploring how (un)fair treatment attributed to a leader is similar to or different from (un)fair treatment attributed to others (e.g., the organization; Lavelle et al., 2009; Liao and Rupp, 2005). This has produced a robust body of research informing scholars about which dimension of justice is most strongly related to specific organizational outcomes, and how leaderfocused justice more strongly predicts affective and behavioural employee outcomes than justice attributed to other organizational entities (Colquitt et al., 2013; Rupp et al., 2014). However, research has neglected to explore the specific behaviours of the leader that relate to these justice dimensions.

The second purpose of this study is to assess the joint effects of leadership and justice in explaining social exchange quality (i.e., leader-member exchange, LMX) and employee outcomes (i.e., task performance and job satisfaction). Accumulated meta-analytic research to date has found that leader behaviours and justice perceptions have similar relationships with employee outcomes. For example, the effect size estimate for the relationship between leader-focused justice perceptions and task performance reported in a leader behaviour meta-analysis is .28 (Podsakoff et al., 2006), whereas organizational justice meta-analyses have reported this relationship to range from .16 to .27 (Colquitt et al., 2013; Rupp et al., 2014). Therefore, existing research has examined the independent relationships of leader behaviours and justice perceptions with employee outcomes, but not the joint effects nor the relative importance of these predictors when considered together. This is a striking omission given that this examination would provide a more comprehensive view of the effects of a leader's decisions and behaviours.

Thus, we integrate leadership research with organizational justice research to explore how leader behaviours inform justice perceptions. Then, we conduct a meta-analysis $(k$ $=166, \mathcal{N}=46,034)$ to provide effect size estimates of the relationships between leader behaviours and justice dimensions, and we examine the joint effects of leadership and justice on LMX, task performance, and job satisfaction. We find that task, relational, and change leader behaviours differentially inform procedural, distributive, interpersonal, and informational justice perceptions. Additionally, combined leader behaviours and justice perceptions offer a more nuanced explanation for the relationships with social exchange quality and performance outcomes as compared to considering only the independent effects of leadership behaviours or justice on outcomes.

Using meta-analysis for this study has several strengths including serving as a tool for theory development related to effective leader behaviours and organizational justice (Combs et al., 2011; Hunter and Schmidt, 2004). Therefore, we develop new theory that describes how leader behaviours have direct implications for justice perceptions. We point to the omission of, and the need for, current leadership theories to clearly articulate the importance of fairness in leader behaviours, and we describe how taking a more comprehensive view of the decisions and behaviours of the leader, by integrating leader behaviours and justice perceptions, is critical to accurately assessing the impact of a leader on employee outcomes. 


\section{THEORETICAL BAGKGROUND}

One purpose of this meta-analysis is to investigate behaviours that inform leaderfocused justice perceptions. We therefore examine leader behaviours that are related to four dimensions of organizational justice referenced to the leader (i.e., leader-focused distributive justice, leader-focused procedural justice, leader-focused interpersonal justice, leader-focused informational justice; Colquitt, 2001; Colquitt et al., 2013). Further, given that leaders are often viewed as representatives of the organization (Eisenberger et al., 2010; Levinson, 1965), we also consider how leader behaviours affect perceptions of organization-focused distributive justice and organization-focused procedural justice. ${ }^{1}$

The four dimensions of justice are based on distinct assessments of fairness in organizational decision-making. Perceptions of distributive justice, the perceived fairness of outcomes, are based on an employee comparing the ratio of his or her inputs and outcomes to the inputs and outcomes of referent others (Adams, 1965; Ambrose and Arnaud, 2005). Procedural justice suggests that individuals evaluate fairness not just on outcomes, but also on fairness in the decision-making process and the ability to have voice in this process (Levanthal, 1980; Thibaut and Walker, 1975, 1978). Interpersonal justice reflects fairness perceptions of interpersonal treatment, and informational justice reflects fairness perceptions of the adequacy and truthfulness of explanations (Colquitt, 2001; Greenberg, 1993).

Justice research is grounded in social exchange theory (SET; Colquitt et al., 2013; Gouldner, 1960; Rupp and Cropanzano, 2002), and this theory provides an important basis for a contextual understanding of the leader-employee relationship. Social exchange relationships are characterized by a high frequency of interactions and task interdependence. Additionally, a characteristic of SET is the notion of time - including knowledge of past actions and an expectation of future obligations (Blau, 1964; Gouldner, 1960). Colquitt et al. (2013) suggested that justice attributed to a particular source has expansive time bracketing, lacking a discrete beginning and end. Therefore, in a social exchange relationship, employees are not evaluating a justice 'event' but an 'entity' with whom the employee has considerable interactions. Indeed, Cropanzano and colleagues (2001) argued that the 'key issue regarding the relationship paradigm is that respondents are judging the fairness of [the leader]... over time and/or across situations' (p. 190). Consequently, perceptions of leader-focused justice are likely to take into account numerous decisions and behaviours made by the leader given the number of interpersonal exchanges in the relationship (Colquitt, 2008).

Managerial role theory has identified decision-making as a key role requirement of leaders in organizations (Dierdorff et al., 2009; Mintzberg, 1973), and numerous scholars have maintained that decision-making is a core component of effective leader behaviours (e.g., Borman and Brush, 1993; Tett et al., 2000; Yukl, 2012). Examples of decision-making responsibilities include planning how to organize and prioritize work; determining how to allocate resources; and assigning responsibilities. Many of these decisions have fairness implications for employees. Employee justice perceptions, 
therefore, are likely to be based on observation and assessment of numerous leader decisions. To be precise, each leader decision provides employees with information to potentially (re-)assess the fairness of the leader as well as information to (re-)evaluate the effectiveness and competence of the leader (Masterson and Lensges, 2015). Employees, therefore, can both assess the behaviour and appraise the fairness of their leader in their interactions. As a result, we suggest that there is a reciprocal relationship between leader behaviours and justice perceptions and that both of these assessments can inform perceptions of the leader.

However, decision-making is only one of several key role requirements for organizational leaders. In fact, Yukl (2012) identified three meta-categories of effective leader behaviours based on an analysis of 50 years of research. ${ }^{2}$ The first meta-category, task leader behaviours, includes previous research on transactional leadership, initiating structure, and contingent reward behaviours (Bass, 1985; Burns, 1978; Fleishman, 1953). Task leader behaviours are focused on efficient use of resources, and they include planning, solving problems, and monitoring progress toward goals (DeRue et al., 2011; Yukl et al., 2002). Task leader behaviours clearly convey information about expectations and standards to clarify employee responsibilities. Therefore, effective task leaders also emphasize and make allocation decisions related to discretionary and formal rewards for job performance (Howell and Avolio, 1993).

The second meta-category, relational leader behaviours, is focused on supporting, recognizing, developing, and empowering individuals (Yukl, 2012). These leader behaviours demonstrate consideration, concern, respect, empathy, and socioemotional support for subordinates (Fleishman, 1953; Greenleaf, 1977). Effective relational behaviours negotiate conflict, encourage participation, and focus subordinate attention on group welfare in their own actions and decision making (Bass, 2008). Relational leaders also are participative in that they seek input from employees, and they treat all group members as equals (Brower et al., 2000).

Finally, the third meta-category, change leader behaviours, is focused on facilitating and driving change and innovation within an organization (Yukl, 2012). Change leader behaviours include developing and communicating a vision for change; encouraging subordinates to be creative and to take risks; and seeking alternate perspectives on challenges facing the group (Bass, 1985; Howell and Avolio, 1993). Several dimensions of transformational leadership theory are included in effective change leader behaviours including charisma, inspirational motivation (i.e., inspiring employees to perform at high levels), intellectual stimulation, and idealized influence (Bass, 1985). Further, change leader behaviours include upholding high ethical standards (Bass, 1985).

The three categories of effective behaviours - task, relational, and change - involve distinct behaviours and decisions of a leader. Thus, these leader behaviours are expected to have different implications for justice perceptions. Therefore, we now turn to examining how task, relational, and change leader behaviours uniquely inform procedural, distributive, interpersonal, and informational justice perceptions. 


\section{HYPOTHESES}

\section{Leader Behaviours and Leader-Focused Procedural Justice}

The most prevalent area of leadership and justice research examines leader behaviours and procedural justice. Procedural justice refers to perceptions of fairness in decision making processes (Colquitt, 2001), and two dominant theories attempt to describe why employees are concerned with fair processes. The control theory perspective, also referred to as the self-interest or instrumental model, argues that employees value voice in the decision-making process because of the potential connection to the resulting outcome (Thibaut and Walker, 1975, 1978). Levanthal (1980) further developed control theory by articulating six rules for fair procedures. These include the consistency rule whereby consistent decisions are made across time and persons. The bias suppression rule which suggests that the decision maker should remove personal biases/interests in the decision-making process. The accuracy rule relates to procedures being followed that are based on valid information. The correctability rule provides a mechanism to reverse a decision. The representativeness rule ensures that procedures reflect the concerns of those impacted by the decision, and the ethicality rule ensures that decisions conform to moral and ethical standards.

The second theoretical perspective, the relational model, proposes that there are psychological aspects of procedural justice that are not covered by control theory, and it argues that individuals care about procedural justice because of the relational messages communicated through fair processes (Blader and Tyler, 2015; Lind and Tyler, 1988). Therefore, fairness in the decision-making process matters not solely because of control or voice, but because it reaffirms group values and relational status in the decision-making process (Tyler and Blader, 2000). Tyler and Lind (1992) further suggest that people seek identity-relevant information through interactions with leaders and that when leaders demonstrate concern in the decision-making process, they convey socioemotional support as well as social standing through these interactions. Numerous empirical studies have found support for the combined effects of the control theory perspective and the relational model of procedural justice (e.g., Lind et al., 1990; Tyler, 1989).

Based on employee concerns for both control and the relational messages conveyed in fair processes, two leader behaviour categories are most likely to inform perceptions of leader-focused procedural justice. First, effective task leader behaviours involve structuring tasks, standardizing procedures, and ensuring rules are followed in a systematic format. These behaviours are likely to satisfy an individual's control needs for consistency, bias suppression, accuracy, and correctability (Holtz and Harold, 2013). Second, effective relational leader behaviours involve consulting employees about matters that affect them which conveys standing to employees as well as fulfilling their needs for representativeness in the decision-making process (Yukl, 2012). Relational leaders also demonstrate consideration and support which affirms relational status (Holtz and Harold, 2013). Finally, relational leaders also regularly offer praise and recognition which signal group values and make employees feel that decisions are consistent ( $\mathrm{gg}$, 2017). Conversely, change leader behaviours are focused on communicating and inspiring. Therefore, even though the ethical elements of change leader behaviours may be related to the ethicality 
rule, the majority of needs articulated in the control theory perspective are related to task leader behaviours rather than change leader behaviours.

Hypothesis 1: Task (a) and relational (b) leader behaviours will exhibit a stronger positive relationship with leader-focused procedural justice perceptions than change leader behaviours.

\section{Leader Behaviours and Organization-Focused Procedural Justice}

Levinson (1965) suggested that there is a transference process whereby employees develop a relationship with a leader and ascribe that relationship to the organization. Therefore, employees view leaders not only as 'individuals in their own right' but also as agents, or representatives of the organization (Eisenberger et al., 2010, p. 1086). This process suggests that perceptions of (un)fair treatment by the leader are likely to be viewed, at least partially, as (un)fair treatment by the organization. As such, employees may view fairness and treatment in decision making processes through the lens of the leader acting as an embodiment of the organization because they generalize the decision and treatment from their leader to the organization (Cropanzano et al., 2001; Eisenberger et al., 2002; Stinglhamber et al., 2015). Given this, we suggest that effective task and relational leader behaviours will also inform organization-focused procedural justice perceptions and more so than the change leader behaviours following the rationale described above.

Hypothesis 2: Task (a) and relational (b) leader behaviours will exhibit a stronger positive relationship with organization-focused procedural justice perceptions than change leader behaviours.

\section{Leader Behaviours and Leader-Focused Distributive Justice}

Distributive justice research is based in equity (Adams, 1965) and social exchange theories (Blau, 1964). These theories position distributive justice as the perceived fairness of outcomes based on employees comparing 'the ratio of their inputs and outcomes to the inputs and outcomes of referent others. Distributions are [deemed to be] fair to the extent that rewards are proportionally matched to contributions' (Ambrose and Arnaud, 2005, p. 61). Distributive justice perceptions are then based on equity norms of allocation (Adams, 1965; Colquitt, 2001). Subsequent work by Levanthal (1980) described alternate reasons individuals care about distributive justice by calling attention to several issues with equity theory. First, he argued that equity theory took a unidimensional rather than multidimensional conception of fairness. That is, by focusing exclusively on the contribution (i.e., equity) rule, equity theory ignored other standards that could influence distributive justice perceptions including an employee's psychological needs. Second, equity theory only considered the final outcome and not the organizational systems, policies, and practices that can lead to allocations (Levanthal, 1980). Numerous others echoed these criticisms. For example, Greenberg (1993) argued that the original 
theorizing on distributive justice was too narrowly focused on structural matters at the expense of the social determinants of distributive fairness. Greenberg (1993) asserted that the 'interpersonal aspects of justice - which thus far have been appreciated only from a procedural justice perspective - are also involved in the distributive side of justice' (p. 82).

We acknowledge both the structural and more contemporary theorizing based on the personal and social determinants of distributive justice and assert that two leader behaviour categories are most likely to inform perceptions of leader-focused distributive justice: task and change leader behaviours. Effective task leader behaviours involve allocating resources among different employees and activities (Yukl, 2012). Therefore, perceptions of distributive justice are likely to be enhanced based on the perceived fairness of these decisions. Further, task leader behaviours focus on contingent rewards whereby a leader promises specific rewards in exchange for performance (Bass, 1985). Hence, a clear link between employee efforts and rewards is established. Finally, task leader behaviours aimed at initiating structure with standardized work environments and uniform performance guidelines should enhance employee perceptions that reward allocations are made equitably. In a similar vein, effective change leaders uphold high ethical standards and make resource allocations decisions in a way that satisfies personal psychological needs related to equity (Cropanzano et al., 2001; Ng, 2017). That is, change leaders' 'moral values take into account the cost and benefits to all stakeholders, the application of distributive justice, and universal moral principles' when confronting issues related to fairness (Bass, 1985, p. 218). This suggests that change leaders are not only aware of fairness issues, but they are adept at navigating these issues equitably. In contrast, the emphasis of relational leader behaviours is on supporting and recognizing employees which is not the focus of either the structural nor more contemporary theorizing on distributive justice.

Hypothesis 3: Task (a) and change (b) leader behaviours will exhibit a stronger positive relationship with leader-focused distributive justice perceptions than relational leader behaviours.

\section{Leader Behaviours and Organization-Focused Distributive Justice}

As argued above, employees may view leaders as representatives of the organization; and therefore, leader behaviours may impact perceptions of organization-focused distributive justice. Eisenberger et al. (2010) have specifically argued that both task (e.g., directive, evaluative, coaching) and change (e.g., developing and/or communicating a vision) leader behaviours are commonly viewed by employees as activities carried out on behalf of the organization. As a result, when a leader is conducting a performance evaluation, the employee may attribute some portion of the reward allocation decision to the policies, processes, or other structural aspects of the organization rather than exclusively to the leader. Similarly, by communicating a vision to encourage greater inputs, the employee may view potential rewards as coming from the organization rather than exclusively the leader. Therefore, we suggest that effective task and change leader 
behaviours will inform organization-focused distributive justice perceptions as well, whereas relational behaviours are less likely to do so.

Hypothesis 4: Task (a) and change (b) leader behaviours will exhibit a stronger positive relationship with organization-focused distributive justice perceptions than relational leader behaviours.

\section{Leader Behaviours and Interpersonal Justice}

Interpersonal justice focuses on perceptions of interpersonal interactions and the extent to which people are treated with respect when decisions are made and outcomes are determined (Colquitt et al., 2013). Holtz and Harold (2009) have described interpersonal justice as encounter-based in that the social exchange transactions between leaders and subordinates occur frequently. Therefore, they argue that interpersonal justice is more salient than other forms of justice. This is consistent with fairness heuristic theory, part of the relational model of justice, which suggests that subordinates make quick assessments of the fairness of their leaders based on initial justice encounters (Lind, 2001). Relational leaders are especially skilled at sensing the needs of subordinates and showing concern. They listen, provide support, and treat employees with dignity and respect (Bass, 1985; Yukl, 2012). As interpersonal treatment is promoted through respect, status, and showing concern for others, relational leader behaviours are most likely to inform perceptions of leader-focused interpersonal justice. Alternatively, whereas effective task (i.e., structuring tasks, directing activities, coaching) and change (i.e., communicating a vision, encouraging innovation, upholding high ethical standards) leader behaviours may be communicated in a manner that demonstrates respectful treatment, such treatment is not the primary focus of these behaviours.

Hypothesis 5: Relational leader behaviours will exhibit a stronger positive relationship with interpersonal justice perceptions than will either task (a) or change (b) leader behaviours.

\section{Leader Behaviours and Informational Justice}

Informational justice reflects fairness perceptions related to the comprehensiveness and truthfulness of explanations (Colquitt, 2001; Greenberg, 1993). It is also encounter-based in that the frequency of interactions between leaders and subordinates in social exchange relationships offers employees numerous opportunities to assess the fairness of information provided. Effective change leader behaviours involve communicating why changes are necessary for employees (Bass, 1985), and the emphasis on open and comprehensive communication in change leader behaviours allows employees to more fully understand decisions. Further, change leader behaviours encourage employees to seek alternate perspectives, and they promote intellectual stimulation which allows for greater comprehension of an explanation (Zhang et al., 2014). Finally, change leaders generally uphold high ethical standards which should enhance perceptions of the truthfulness 
of the explanation (Bass, 1985). Conversely, task leader behaviours are focused on directing, coaching, clarifying responsibilities, and monitoring progress. Therefore, these behaviours have less of an emphasis on comprehensiveness of information conveyed and more of a transactional focus. Similarly, relational leader behaviours focus on recognizing and showing socioemotional support for employees which is more reflective of empathic communications rather than comprehensive and truthful explanations.

Hypothesis 6: Change leader behaviours will exhibit a stronger positive relationship with informational justice perceptions than will either task (a) or relational (b) leader behaviours.

\section{SOGIAL EXGHANGE QUALITY AND EMPLOYEE OUTCOMES}

The preceding section suggested how leader behaviours inform justice perceptions. We turn now to the second purpose of this study: discussing the joint impact of justice perceptions and leader behaviours in explaining social exchange quality and employee outcomes. Here, we also present a model that describes the nonrecursive nature (i.e., reciprocally interdependent; Bentler and Raykov, 2000) of perceptions of the leader (including both leader behaviours and justice perceptions) as they impact social exchange quality and performance outcomes (see Figure 1).

\section{Social Exchange Quality}

The quality of the social exchange relationship between a leader and subordinate is commonly assessed by examining LMX (Graen and Scandura, 1987; Liden and Maslyn, 1998). Studies have argued and found support for assertions that both justice perceptions and leader behaviours enhance the quality of social exchange directly or indirectly (e.g., Wayne et al., 2002). However, what is lacking from current research is a better understanding of which leader behaviours or justice dimensions have greater

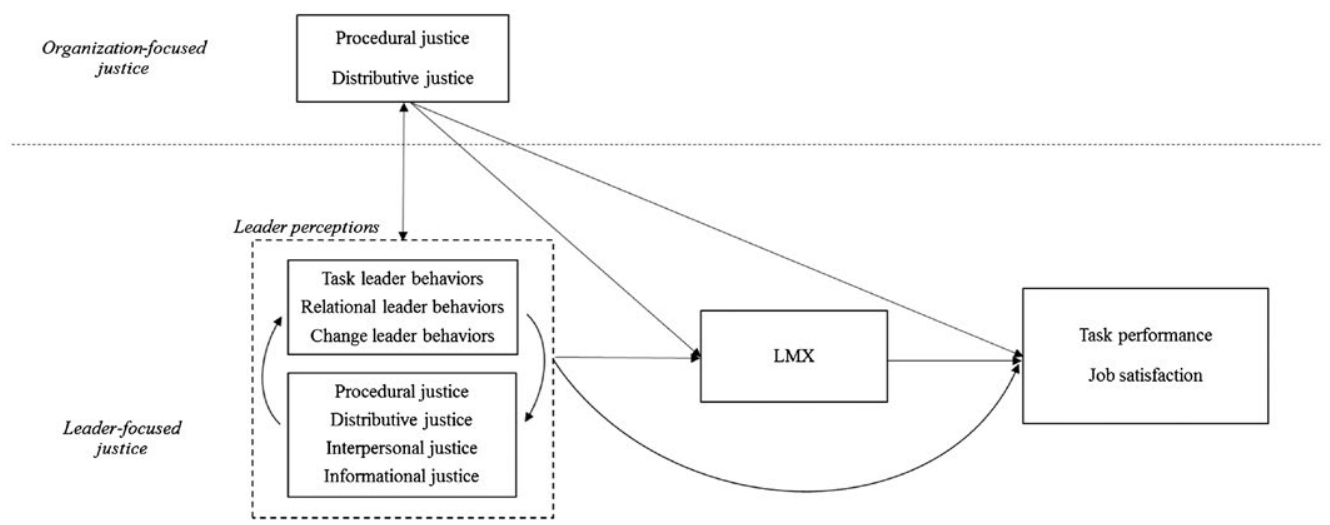

Figure 1. Conceptual model of organizational justice, effective leader behaviours, social exchange quality, and subordinate outcomes 
influence on LMX when considered jointly. The target similarity model in the organizational justice literature predicts that there will be stronger relationships between target similar justice perceptions and outcomes (e.g., leader-focused justice $\rightarrow$ perceived leader support $\rightarrow$ leader-directed citizenship behaviour) than target dissimilar justice perceptions and outcomes (e.g., leader-focused justice $\rightarrow$ perceived organizational support $\rightarrow$ organization-directed citizenship behaviour; Lavelle et al., 2007). Accordingly, leader-focused justice perceptions should have a stronger relationship with LMX than organization-focused just perceptions. Yet neither the target similarity model nor any theories of leadership specifically address how justice, combined with assessments of the leader's behaviours, will influence social exchange quality. Therefore, given that these perceptions are based on numerous interactions with the focal leader, existing research has an incomplete understanding of the joint effects and relative importance of justice and leader behaviours in explaining LMX. Therefore, we pose the following research question:

Research question 1: When considered simultaneously, what unique contributions do leader behaviours and justice dimensions make to explaining variance in LMX, and what is the relative important of these contributions?

\section{Task Performance and Job Satisfaction}

Extant research has demonstrated strong, positive relationships between both leader behaviours and justice perceptions and employee task performance and job satisfaction (Colquitt et al., 2013; DeRue et al., 2011; Podsakoff et al., 2006; Rupp et al., 2014). Indeed, the dominant focus of both leader behaviour and justice research has been the prediction of these outcomes. However, there are conflicting theoretical arguments as to whether leader behaviours or justice dimensions have greater influence on subordinate outcomes when considered jointly. For example, Kirkman et al. (2009) suggest that justice will be a stronger predictor of outcomes, and they assert that leader behaviours are a 'more distal and ambient stimuli' than justice perceptions because leader behaviours are directed broadly to all individuals in a group (p. 748). Conversely, they argue that justice perceptions vary between individuals, and therefore are more proximal to (and will have a greater effect on) subordinate behaviours. An alternate argument proposed by De Cremer et al. (2007) suggests that leader behaviours exert a stronger influence on outcomes because justice practices simply create the essential conditions for leadership to emerge. That is, fair practices 'create a psychological platform' on which appraisals of leadership are built which motivate follower performance more directly (De Cremer et al., 2007, p. 1798). In other studies (e.g., Wayne et al., 2002), authors do not make predictions about whether leader behaviours or justice dimensions will have a greater impact on outcomes. Instead, they consider both as unique antecedents and do not address which is expected to have a greater effect on outcomes.

Given this accumulation of research, and the divergence in theorizing related to the effects of leader behaviours and justice perceptions on subordinate outcomes, the 
joint effect and relative importance of these predictors when considered simultaneously remains unclear. Therefore, we pose the following second research question:

Research question 2: When considered simultaneously, what unique contributions do leader behaviours and justice dimensions make to explaining variance in (a) task performance and (b) job satisfaction, and what is the relative importance of these contributions?

\section{DATA AND METHODOLOGY}

\section{Literature Search and Inclusion Criteria}

To identify empirical studies related to leader behaviours and organizational justice, we relied on several sources. First, we performed a literature search in four databases (PsycINFO, ISI Web of Science, Business Source Complete, and ProQuest Dissertations \& Theses) for published studies, dissertations, and theses from 1900 to December 2017. The search was conducted using the term leader* as well as the justice-related keywords from Colquitt et al. (2001): procedural fairness, procedural justice, distributive fairness, distributive justice, interactional justice, interpersonal treatment, interpersonal justice, informational justice, and equity. Second, we searched for additional studies by sending emails through three Academy of Management (AOM) division listserves (Human Resources Division List, Network for Leadership Scholars, and Organizational Behavior Division List) requesting published and unpublished studies that examined the relationship between leadership and organizational justice. Third, we searched the previous six years (i.e., 2012-17) of conference programs from the AOM and the Society for Industrial and Organizational Psychology to identify presented papers examining leader behaviours and organizational justice. Emails were then sent to the first authors of these conference papers requesting the unpublished manuscripts. These searches yielded an initial population of 760 studies to review for possible inclusion.

Next, we examined these studies in detail to determine if they met the following inclusion rules established for this study. First, the study had to include both a leadership variable and an organizational justice variable. Second, the study had to report an effect size in a correlation matrix or other relevant information that could be used to calculate a zero-order correlation. Third, the study had to include a unique sample. If a sample was used in multiple studies, only one study was included; however, articles that included multiple studies with independent samples were coded separately. Fourth, we included only individual-level effect sizes and excluded group- or organizational-level data.

Of the 760 studies in our initial population, 145 met all of these criteria, comprising 126 published studies, 19 unpublished manuscripts, and 166 independent samples $(\mathcal{N}=$ 46,034). Table I lists the primary studies coded for this meta-analysis. 
Table I. Studies included in the meta-analysis

\begin{tabular}{|c|c|}
\hline Academy of Management fournal & Human Performance \\
\hline Erdogan et al. (2006) & Johnson et al. (2009) \\
\hline Kirkman et al. (2009) & Spector and Che (2014) \\
\hline Korsgaard et al. (1995) & Human Relations \\
\hline Masterson et al. (2000) & Cobb and Lau (2015) \\
\hline Tekleab et al. (2005) & El Akremi et al. (2010) \\
\hline Tepper $(2000)$ & Keller and Dansereau (1995) \\
\hline Zhang et al. (2014) & Murphy et al. (2003) \\
\hline Academy of Management Learning \& Education & International Fournal of Contemporary Hospitality Management \\
\hline Graen et al. (2006) & Dai et al. (2013) \\
\hline African Fournal of Business Management & International fournal of Hospitality Management \\
\hline Katrinli et al. (2010) & Luo et al. (2014) \\
\hline Asian Fournal of Social Psychology & International Fournal of Human Resource Management \\
\hline Jiang and Cheng (2008) & Tuytens and Devos (2012) \\
\hline Australian Fournal of Management & Lee and Wei (2017) \\
\hline Georgalis et al. (2015) & International Fournal of Nursing Studies \\
\hline Brazilian Business Review & Gillet et al. (2013) \\
\hline Cavazotte et al. (2013) & International Fournal of Sports Science $\mathcal{E}^{\circ}$ Coaching \\
\hline Decision Support Systems & Kim and Andrew (2015) \\
\hline Tsay et al. (2014) & International fournal of Stress Management \\
\hline Educational and Psychological Measurement & Riolli and Savicki (2006) \\
\hline Kacmar et al. (1999) & International Public Management Fournal \\
\hline Employee Relations & Potipiroon and Faerman (2016) \\
\hline Katou (2015) & Fournal of Applied Behavioral Science \\
\hline European Fournal of Social Psychology & Wu et al. (2007) \\
\hline De Cremer and den Ouden (2009) & Fournal of Applied Psychology \\
\hline European Fournal of Work and Organizational & Choi (2008) \\
\hline Psychology & Colquitt (2001) \\
\hline De Cremer (2006) & Colquitt et al. (2012) \\
\hline Gaudet et al. (2014) & De Cremer and Van Knippenberg (2002) \\
\hline Mayer et al. (2008) & De Cremer et al. (2005) \\
\hline Piccolo et al. (2008) & Dineen et al. (2006) \\
\hline Sparr and Sonnentag (2008) & Korsgaard et al. (2002) \\
\hline European Management Fournal & Rhoades et al. (2001) \\
\hline Grover and Coppins (2012) & Thau and Mitchell (2010) \\
\hline Gender, Work and Organization & Wayne et al. (2002) \\
\hline Cole (2004) & Journal of Applied Social Psychology \\
\hline Group \& Organization Management & Cobb and Frey (1996) \\
\hline Camerman et al. (2007) & De Cremer et al. (2007) \\
\hline Carter et al. (2014) & Heck et al. (2005) \\
\hline Cropanzano et al. (2002) & Lin et al. (2009) \\
\hline Frazier et al. (2010) & \\
\hline
\end{tabular}

(Continued) 
Table I Continued)

Fournal of Business and Psychology

Burton et al. (2008)

Tremblay et al. (2013)

Walsh et al. (2018)

Fournal of Business Ethics

Chiaburu and Lim (2008)

Hsiung (2012)

$\mathrm{Xu}$ et al. (2016)

Journal of Business Research

DeConinck (2010)

Gumusluoglu et al. (2013)

Fournal of Experimental Social Psychology

van Dijke and De Cremer (2010)

Fournal of International Business Studies

Pillai et al. (1999)

Journal of Leadership \& Organizational Studies

Song et al. (2012)

Strom et al. (2014)

Tremblay et al. (2018)

Fournal of Management

Elicker et al. (2006)

Karriker and Williams (2009)

Pillai et al. (1999)

Roch and Shanock (2006)

Rosen et al. (2011)

Journal of Marketing

Netemeyer et al. (1997)

Fournal of Organizational Behavior

Andrews and Kacmar (2001)

Aryee et al. (2002)

Epitropaki (2013)

Erdogan and Liden (2006)

He et al. (2016)

Holtz and Harold (2013)

Khazanchi and Masterson (2011)

Ogunfowora (2013)

Walumbwa et al. (2009)

Xu et al. (2012)

Journal of Organizational Change Management

Kool and van Dierendonck (2012)
Journal of Personnel Psychology

Camps et al. (2012)

fournal of Social Psychology

Chi and Lo (2003)

Leadership

Kim and $\operatorname{Kim}$ (2015)

Leadership \& Organization Development Fournal

Ansari et al. (2007)

Bhal (2006)

Bhal and Ansari (2007)

Chiaburu and Marinova (2006)

Fein et al. (2013)

Fuchs (2011)

The Leadership Quarterly

Cho and Dansereau (2010)

Haynie et al. (2014)

Sun et al. (2013)

Walumbwa et al. (2008)

Yang et al. (2009)

Management and Organization Review

Chen et al. (2009)

Li et al. (2014)

Wu et al. (2012)

Military Psychology

Tremblay (2010)

New Educational Review

Ishaq et al. (2012)

Organization Science

Hui et al. (2004)

Organizational Behavior and Human Decision Processes

Johnson et al. (2006)

Lian et al. (2012)

Martinko et al. (2007)

van Dijke et al. (2012)

Walumbwa et al. (2011)

Personnel Psychology

Ehrhart (2004)

Mansour-Cole and Scott (1998)

(Continued) 
Table I (Continued)

\begin{tabular}{ll}
\hline \hline Personnel Review & Strategic Change \\
Connell et al. (2003) & Ferres et al. (2005) \\
Tuytens and Devos (2012) & Conference Papers \\
Wat and Shaffer (2005) & Rhodes et al. (2013) \\
Psychological Reports & Dissertations \\
Tziner et al. (2008) & Anand (2012) \\
Procedia-Social and Behavioral Sciences & Burlacu (2013) \\
Zeinabadi and Rastegarpour (2010) & Hoobler (2002) \\
Public Administration Review & Kiersch (2012) \\
Hassan et al. (2014) & Lam (2010) \\
Public Management Review & Li (2012) \\
Gould-Williams and Davies (2005) & Morrison (2015) \\
Public Personnel Management & Mosley (2006) \\
Chen and Jin (2014) & Oginde (2013) \\
Review of Public Personnel Administration & Ren (2008) \\
Meng and Wu (2015) & Roberts (2004) \\
Revista De Psicología Del Trabajo Y De Las & Sanchez (2006) \\
Organizaciones & Shalhoop (2004) \\
Chernyak-Hai and Tziner (2014) & Shull (1995) \\
Service Industries Fournal & Simon (1995) \\
Kang et al. (2012) & White (2008) \\
Social Behavior and Personality & Williams (2012) \\
Huang et al. (2015) & Wilson (2011) \\
\hline \hline
\end{tabular}

\section{Data Coding}

As suggested by meta-analytic reporting standards (Kepes et al., 2013), the data coding process was guided by a set of protocols. First, we generated a list ofleader behaviours and organizational justice constructs guided by prior meta-analytic studies (Colquitt et al., 2001, 2013; DeRue et al., 2011; Rupp et al., 2014). If the study met the inclusion criteria above (i.e., contained both a leadership variable and a justice variable), we proceeded to code the correlations for the study variables. We articulated definitions for each of the coded constructs along with a list of common variable names to ensure consistency in coding among authors. An excel worksheet with macros was designated as the standard coding sheet to capture relevant information defined by the protocols. This information included the measures, correlations, means, standard deviations, and reliabilities for all study variables. In addition, we captured the country where the data was collected, the context for the study (e.g., field, lab), and we noted whether the study was published or unpublished. ${ }^{3}$ 
Leader behaviours. Consistent with the definitions provided in Yukl (2012) and DeRue et al. (2011), correlations that included leader behaviours were coded as either task, relational, or change. Task leader behaviours are job-focused behaviours aimed at defining task roles and role relationships. Theyincluded initiating structure, contingent reward, and management by exception-active (DeRue et al., 2011). Relational leader behaviours focus on providing socioemotional support and demonstrating concern and respect. They include consideration (Bass, 1990), empowering leadership (Conger, 1989), and participative leadership (Kahai et al., 1997). Change leader behaviours are focused on developing and communicating a vision of change, encouraging innovation, and facilitating collectivelearning. Theyinclude the transformationalleadership dimensions of charisma, inspirational motivation, intellectual stimulation, and idealized influence, and visionary leadership (Bass, 1985).

Organizational justice. Following the protocols in existing meta-analyses (Colquitt et al., 2013; Rupp et al., 2014), we coded correlations that included justice variables by dimension (i.e., procedural, distributive, interpersonal, or informational) and by source, the party referenced as the 'deliverer' of the (un)just treatment (leader-focused or organizationfocused). We determined the type and source by examining the specific scale item(s) and item instructions in the method section. Consistent with the coding details provided by Rupp et al. (2014), we found that justice type was most often labeled explicitly whereas justice source was not. Therefore, again following the coding protocol of Rupp et al. (2014), when information about the source of justice in the method section was ambiguous, we would review the theoretical arguments and hypotheses to make a coding determination about the justice source. In the case of conflicting information about the source between the method and theory sections, we used the source defined by the scale items or instructions. Our final dataset consists of correlations with six justice variables: leader-focused procedural justice, leader-focused distributive justice, (leader-focused) interpersonal justice, (leader-focused) informational justice, organization-focused procedural justice, and organizationfocused distributive justice.

Social exchange quality and subordinate outcomes. ${ }^{4}$ To capture the social exchange quality between the leader and subordinate, we coded bivariate correlations with $L M X$ as a leader-referent social exchange variable (Graen and Scandura, 1987; Liden and Maslyn, 1998). We also coded correlations that included two subordinate outcome variables - one behavioural outcome (i.e., task performance) and one affective outcome (i.e., job satisfaction). Task performance reflects activities that contribute to the production of goods or provisions of services and that are commonly reflected in formal job requirements (Rotundo and Sackett, 2002); and job satisfaction captures the positive cognitive or affective emotional response to one's job (Hulin and Judge, 2003). Consistent with prior research, we conceptualized task performance as a leader-directed outcome variable and job satisfaction as a global, organization-directed outcome variable for purposes of comparing findings with the target similarity model (Cropanzano et al., 2002; Rupp and Cropanzano, 2002; Rupp et al., 2014). 


\section{ANALYSIS AND RESULTS}

\section{Analytical Procedures}

We used the procedures recommended by Hunter and Schmidt (2004) in conducting the meta-analysis. We corrected for sampling error and for measurement unreliability in the reported correlations using the Cronbach's alpha statistics reported in the study. In the small number of cases where reliability information for a variable was not reported, we employed the average reliability of all other studies that did report reliability data for that variable (Hunter and Schmidt, 2004). In addition, several studies reported multiple estimates of the same bivariate relationship (e.g., procedural justice and LMX). For these cases, we created a composite correlation for the relationship of interest (Colquitt et al., 2013; Hunter and Schmidt, 2004). We report the results of the meta-analysis for the relationships between leader behaviours and referent-specific justice dimensions in Table II. For each bivariate relationship, we report the number of studies $(k)$; the sample size $(\mathcal{N})$; the uncorrected $\left(\rho_{\mathrm{u}}\right)$ population correlation and the $95 \%$ confidence interval $(\mathrm{CI})$ around this value; the corrected $\left(\rho_{\mathrm{c}}\right)$ population correlation and the $80 \%$ credibility interval $(\mathrm{CV})$ around this value; the standard deviation of the corrected population correlation $\left(\mathrm{SD}-\rho_{\mathrm{c}}\right)$; the percentage of variance in each population correlation explained by study artifacts $\left(\% \mathrm{~V}_{\text {art }}\right)$; and the homogeneity test score $(\mathrm{Q})$. Further, as biases may exist in our effect estimates due to selective publication of studies, we conducted Duval and Tweedie's (2000) nonparametric 'trim and fill' analyses of publication bias employing the metatrim command in Stata (Steichen, 2000). We report the additional imputed studies $(\Delta k)$ and the adjusted population correlation $\left(\operatorname{adj}-\rho_{c}\right)$ resulting from this analysis in Table II.

To analyse the hypotheses, we first created a meta-analytically derived correlation matrix for all variables in the study using our coded data. Then, we compared the meta-analytic corrected population correlations from this study to published meta-analytic estimates. Where published meta-analytic data was available, we replaced the value in our original data with the published corrected correlation in subsequent analyses unless our data had a higher $k$ and $\mathcal{N}$ than the published data. In these cases, we retained our original data. ${ }^{5}$ The meta-analytic source of the substitutions and the meta-analytic values are presented in Tables III, IV respectively.

Employing the resultant meta-analytic correlation matrix, we conducted a dominance analysis (DA) for each hypothesis to investigate the relative importance of leader behaviours in predicting justice perceptions (Budescu, 1993). DA is a qualitative comparison of the relative importance of predictors in multiple linear regression (MLR), and it is robust to issues of multicolinearity because the approach is based on a predictor's added predictive ability in the presence of other predictors. Further, it is more 'sensitive to the various importance patterns that can emerge' relative to other analytic techniques (Azen and Budescu, 2003, p. 124). Thus, DA is a superior statistical approach to assessing the relative importance of variables, particularly with a set of correlated predictors (Azen and Budescu, 2003). By using DA, we are able to infer which variables are dominant predictors of outcomes when considered in combination with other predictors.

DA calculates and employs the squared multiple correlations of all possible MLR models involving the predictors $\left(2^{\mathrm{p}}-1\right.$ models; $\mathrm{p}=$ number of predictors $)$ to rank order 


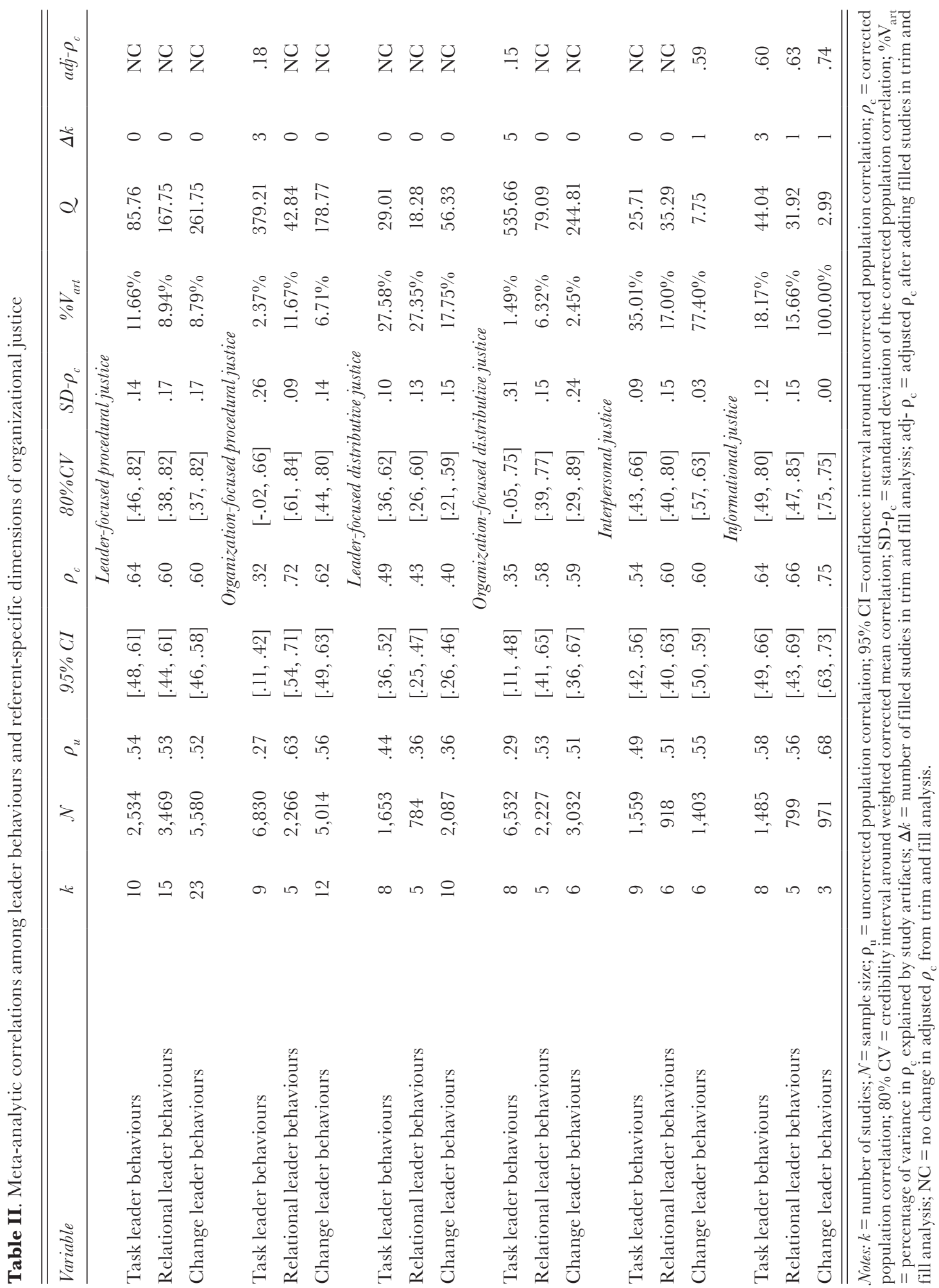




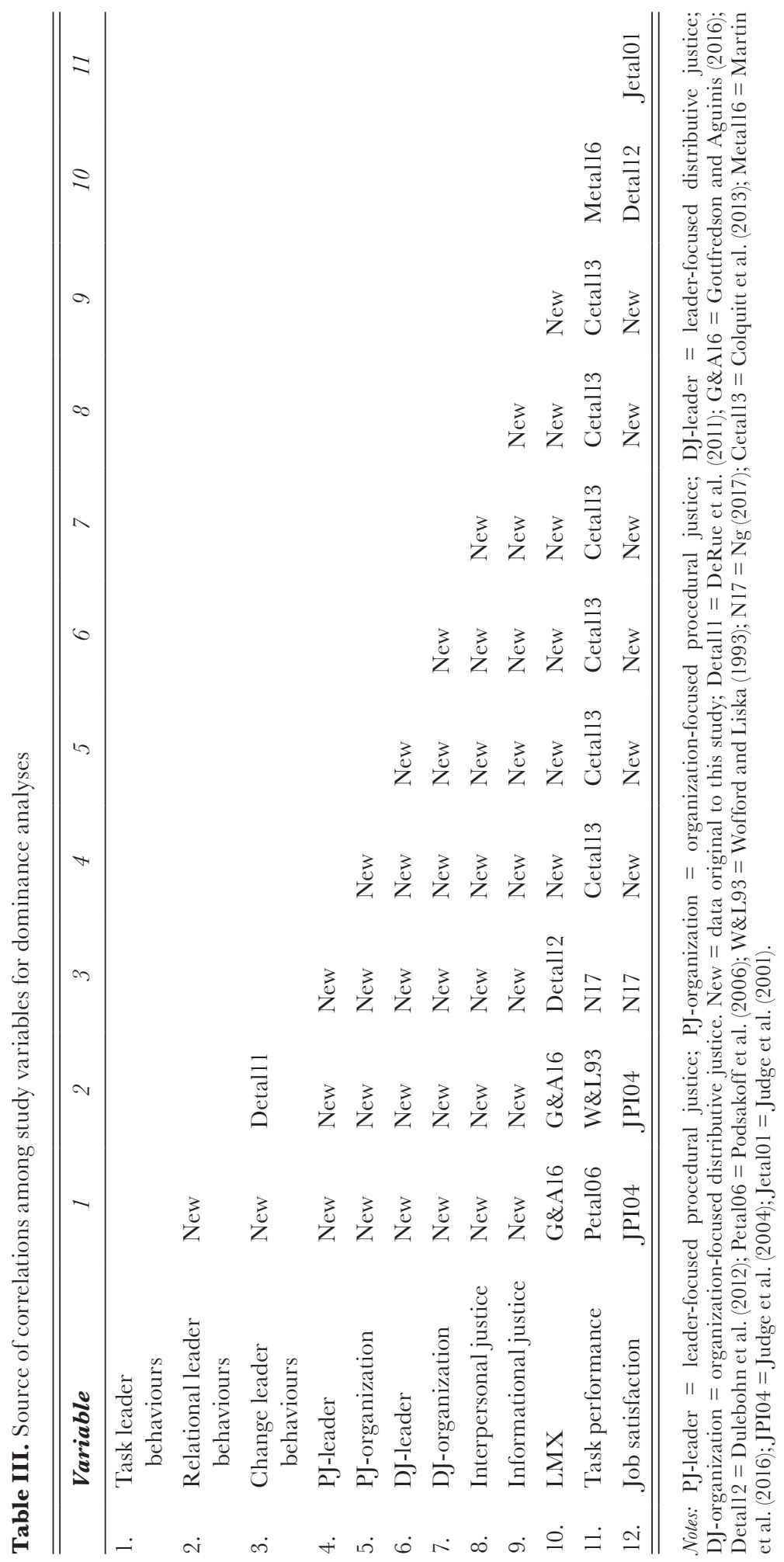

(C) 2018 John Wiley \& Sons Ltd and Society for the Advancement of Management Studies 

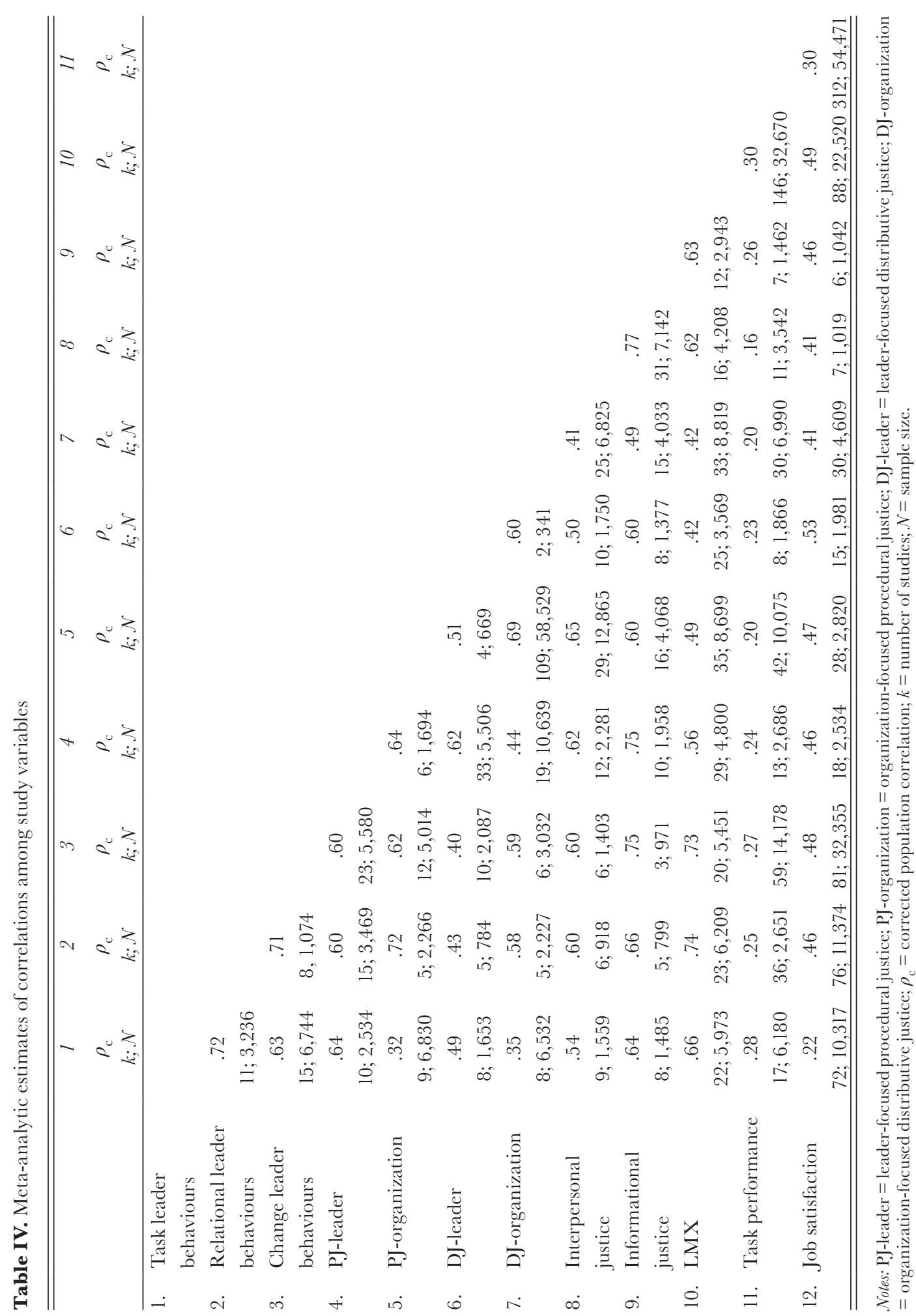
predictors by their relative contribution to total variance explained. (A variety of software packages - e.g., the 'yhat' package in R: https://cran.r-project.org/web/packages/yhat/ index.html - are available to conduct a DA; see Nimon and Oswald, 2013.) The degree to which a focal predictor dominates other predictors is determined by examining the incremental variance explained across the models (Azen and Budescu, 2003). DA 'indicates whether one IV contributes more unique variance than another IV, either (a) across all possible MLR submodels (i.e., complete dominance) or (b) on average across models of all-possible-subset sizes (i.e., conditional dominance); averaging conditional dominance weights yields general dominance weights' (Nimon and Oswald, 2013, p. 652).

Complete dominance occurs when the incremental variance explained by a focal predictor is greater in all possible MLR models than that of the comparison predictor(s). Conditional dominance occurs when the average incremental variance explained by a focal predictor within each model size (i.e., averaged across the subset of models with the same number of predictors) is greater than that of the comparison predictor(s). General dominance occurs when the average of all conditional dominance measures (i.e., average of the average for each model size) for a focal predictor is greater than that of the comparison predictor(s). Notably, the relative weight measure epsilon (Johnson, 2000) reported in many meta-analyses (e.g., DeRue et al., 2011) is an approximation of the general dominance measure. Dominance types are nested based on the strictness of the type's definition: general under conditional and conditional under complete. Because each hypothesis has three leader behaviour predictor variables, there are seven subset models and three subset model sizes for each justice criterion.

The research questions presented in this study attempt to determine the relative importance of leader behaviours and justice variables in explaining LMX, task performance, and job satisfaction. Here again, we employed DA to examine the rank order of predictor variables (Azen and Budescu, 2003; Budescu, 1993). Each research question had three leader behaviour and six justice predictor variables resulting in 511 subset models and nine subset model sizes for each outcome criterion.

\section{RESULTS}

Hypotheses 1-6 were concerned with the relationships between leader behaviours and dimensions of organizational justice (see Tables V-VIII). Specifically, Hypothesis la predicted that task leader behaviours would have a stronger positive relationship with leader-focused procedural justice than change leader behaviours. In support of this, we find that task leader behaviours completely dominate change leader behaviours (i.e., incremental variance explained is greatest for task leader behaviours in all comparison models; see Table $\mathrm{V}$, average $\left.\Delta R^{2}=.19>.15\right)$. Therefore, Hypothesis la was supported. Hypothesis $1 \mathrm{~b}$ predicted that relational leader behaviours would have a stronger positive relationship with leader-focused procedural justice than change leader behaviours. Contrary to this hypothesis, change leader behaviours exhibit general dominance over relational leader behaviours (see Table V, average $\Delta R^{2}=.15>.14$ ). Therefore, Hypothesis $1 \mathrm{~b}$ was not supported.

Hypothesis 2a predicted that task leader behaviours would have a stronger, positive relationship with organization-focused procedural justice than change leader behaviours. 

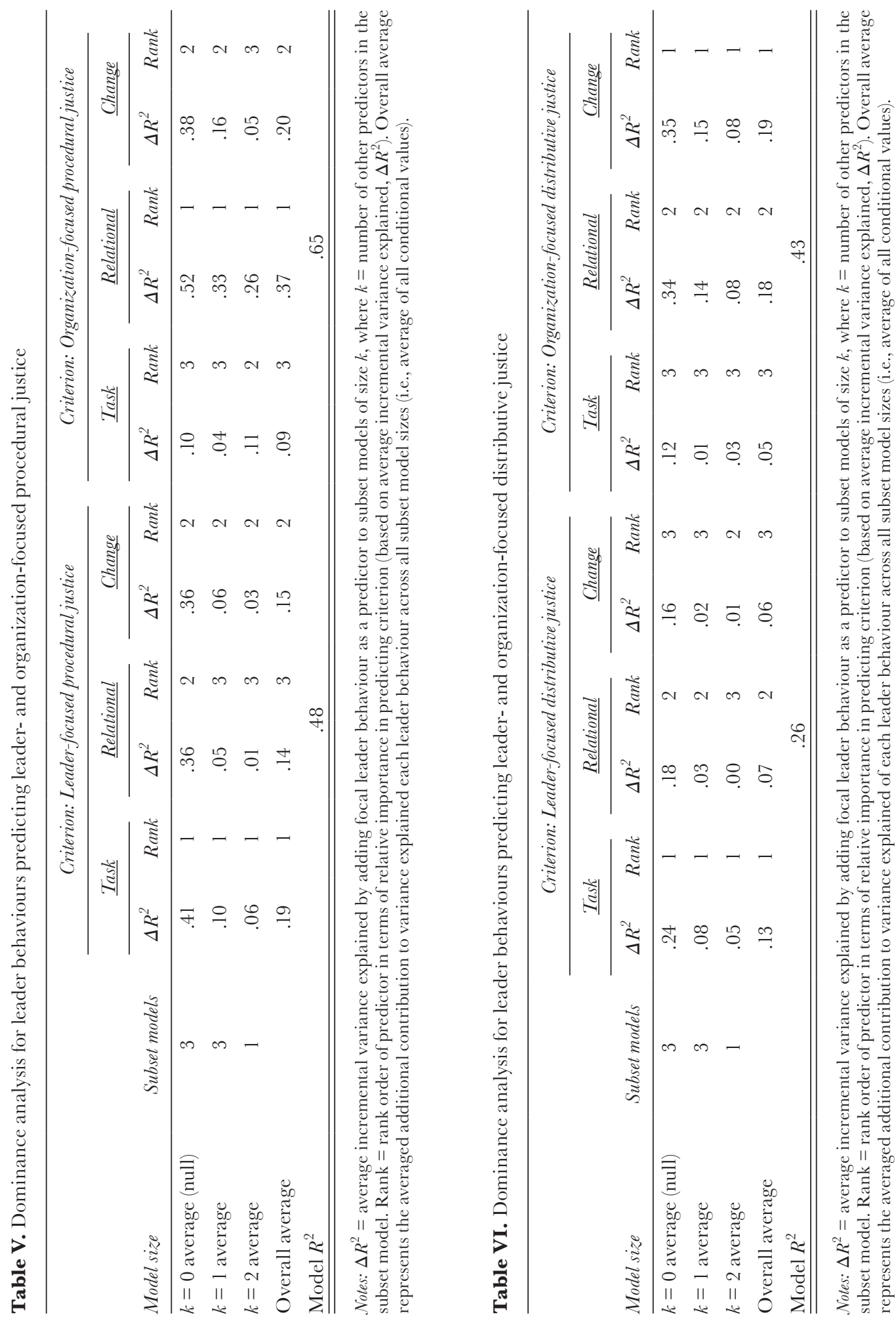


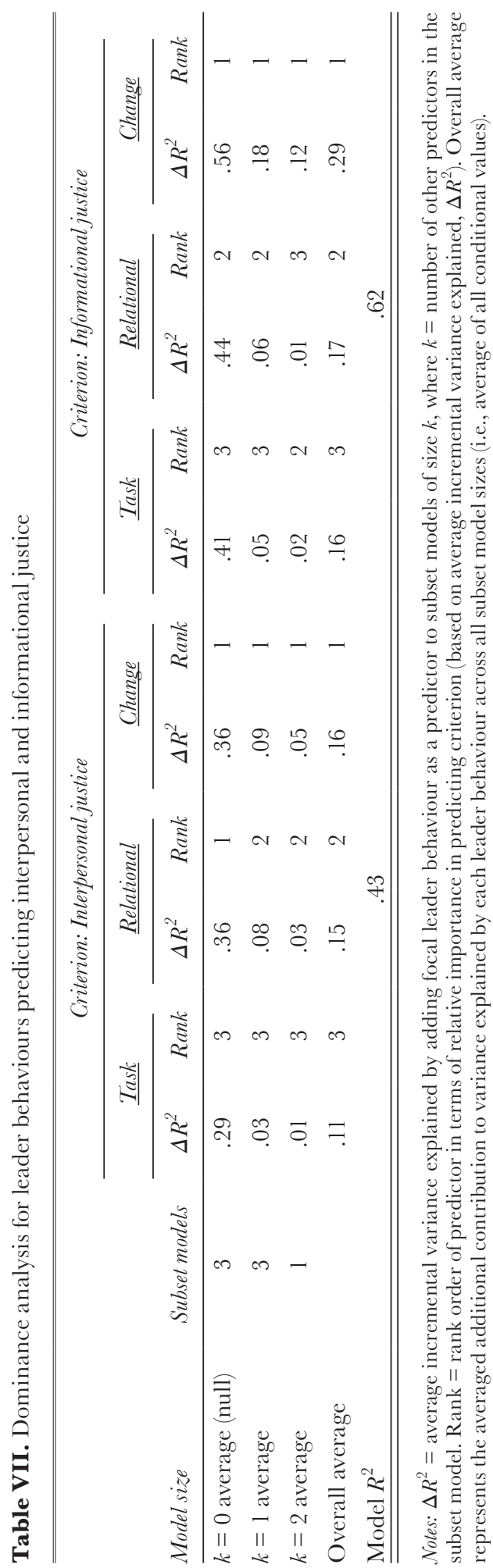




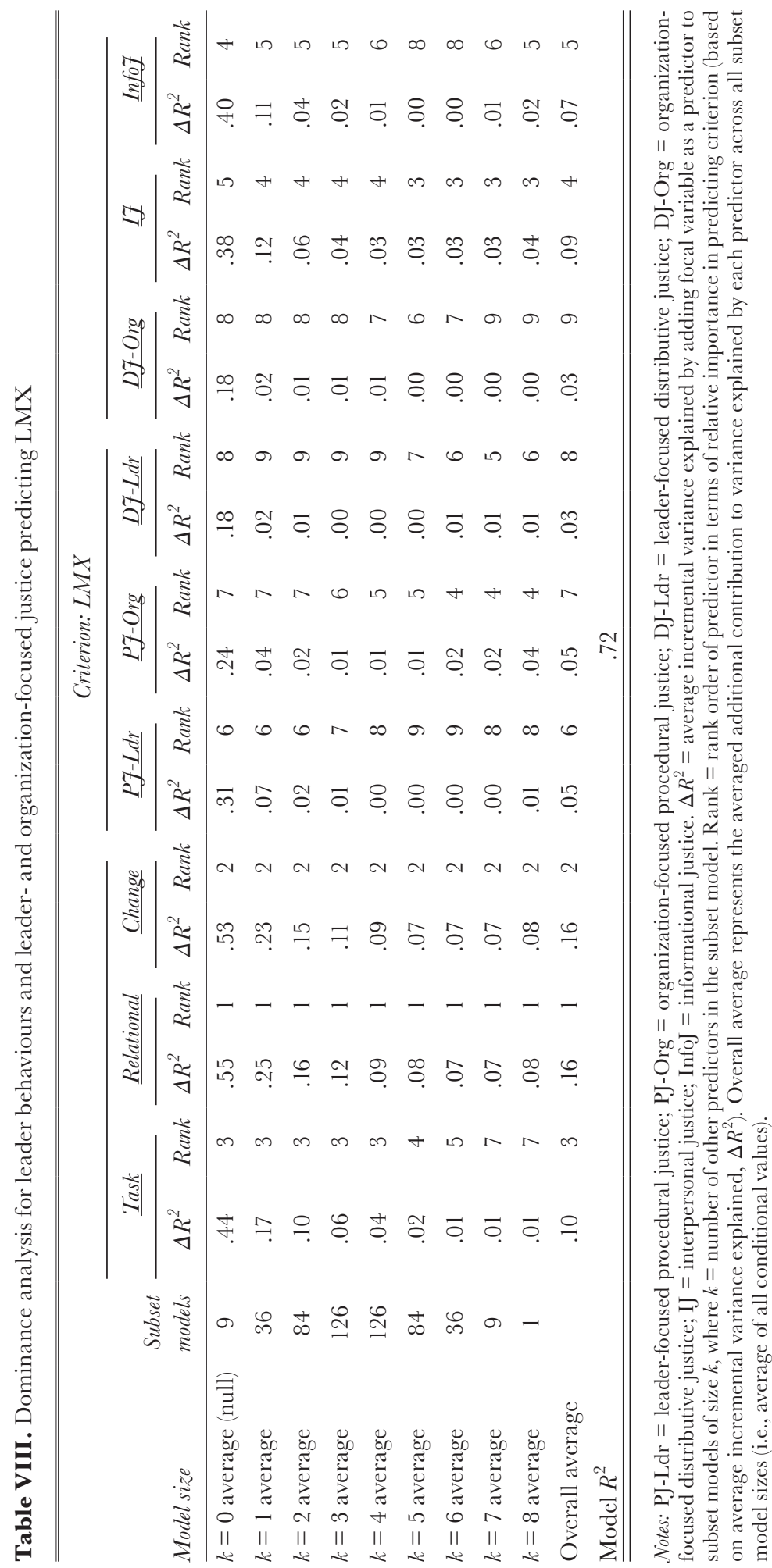


Contrary to this hypothesis, change leader behaviours exhibit general dominance over task leader behaviours (see Table $\mathrm{V}$, average $\Delta R^{2}=.20>.09$ ). Therefore, Hypothesis $2 \mathrm{a}$ was not supported. Hypothesis $2 \mathrm{~b}$ predicted that relational leader behaviours would have a stronger, positive relationship with organization-focused procedural justice than change leader behaviours. In support of this, we find that relational leader behaviours exhibit complete dominance (i.e., incremental variance explained is greatest for relational leader behaviours in all comparison models; see Table $\mathrm{V}$, average $\Delta R^{2}=.37>$ .20). Therefore, Hypothesis $2 \mathrm{~b}$ was supported. Notably, the model $R^{2}$ for leader-focused procedural justice (.48) was less than for organization-focused procedural justice (.65). We return to this in the discussion section.

Hypothesis 3 a predicted that task leader behaviours would have a stronger, positive relationship with leader-focused distributive justice than relational leader behaviours. In support of this, we find that task leader behaviours completely dominate relational leader behaviours (i.e., incremental variance explained is greatest for task leader behaviours in all comparison models; see Table VI average $\left.\Delta R^{2}=.13>.07\right)$. Therefore, Hypothesis $3 \mathrm{a}$ was supported. Hypothesis $3 \mathrm{~b}$ predicted that change leader behaviours would have a stronger positive relationship with leader-focused distributive justice than relational leader behaviours. Contrary to this hypothesis, relational leader behaviours exhibit general dominance over change leader behaviours (see Table VI, average $\Delta R^{2}=.07>.06$ ). Therefore, Hypothesis 3b was not supported.

Hypothesis 4a predicted that task leader behaviours would have a stronger positive relationship with organization-focused distributive justice than relational leader behaviours. Contrary to this hypothesis, relational leader behaviours exhibit complete dominance over task leader behaviours (see Table VI, average $\Delta R^{2}=.18>.05$ ). Therefore, Hypothesis $4 \mathrm{a}$ was not supported. Hypothesis $4 \mathrm{~b}$ predicted that change leader behaviours would have a stronger, positive relationship with organization-focused distributive justice than relational leader behaviours. In support of this, we find that change leader behaviours completely dominate relational leader behaviours (i.e., incremental variance explained is greatest for change leader behaviours in all comparison models, see Table VI, average $\left.\Delta R^{2}=.19>.18\right)$. Therefore, Hypothesis $4 \mathrm{~b}$ was supported. Again, worthy of note was that the model $R^{2}$ for leader-focused distributive justice (.26) was less than for organization-focused distributive justice (.43).

Hypothesis 5 suggested that relational leader behaviours would have a stronger, positive relationship with interpersonal justice than either task (a) or change (b) leader behaviours. Consistent with this prediction, relational leader behaviours had a stronger positive relationship with interpersonal justice than task leadership behaviours (see Table VII, average $\Delta R^{2}=.15>.11$ ). Therefore, Hypothesis 5 a was supported. However, contrary to this prediction, change leader behaviours generally dominate relational leader behaviours (see Table VII, average $\Delta R^{2}=.16>.15$ ). Therefore, Hypothesis 5b was not supported.

Finally, Hypothesis 6 predicted that change leader behaviours would have a stronger positive relationship with informational justice than either task (a) or relational (b) leader behaviours. Incremental variance explained is greatest for change leader behaviours in all comparison models indicating that change leader behaviours completely dominate 
task and relational leader behaviours (see Table VII, average $\Delta R^{2}=.29>.16$ and $.29>$ .17 respectively). Therefore, Hypotheses $6 \mathrm{a}$ and $6 \mathrm{~b}$ were supported.

The research questions were concerned with the relative importance of leader behaviours and justice dimensions in predicting LMX, task performance, and job satisfaction. With regard to research question 1, which assessed the relative importance of leader behaviours and leader-focused justice predictors for LMX, we find that leader behaviours (minimum average $\Delta R^{2}=.10$ ) demonstrate general dominance over the justice predictors (maximum average $\Delta R^{2}=.09$ ). Further, relational leader behaviours exhibit conditional dominance ( $\mathrm{Rank}=1$ for all subset model sizes) over all other predictors and change leader behaviours exhibit conditional dominance $($ Rank $=2$ for all subset model sizes) over all but relational leader behaviours (model $R^{2}=.72$, see Table VIII). Research question 2 investigated the relative importance of leader behaviours and leader- and organization-focused justice predictors on (a) task performance and (b) job satisfaction. For task performance, we find that the general dominance rank order of predictors is task then change leader behaviours followed by informational justice, leader-focused distributive justice, and relational leader behaviours (model $R^{2}=.11$, see Table IX). For job satisfaction, we find that the general dominance rank order of predictors is leader-focused distributive justice first, followed by relational, change, and task leader behaviours, followed by organization-focused procedural justice (model $R^{2}=.58$, see Table $\mathrm{X}$ ). Table XI presents a summary of results for all of the hypotheses and research questions.

\section{DISGUSSION}

Research into the impact of effective leader behaviours and organizational justice has demonstrated significant, positive effects on employee affective and behavioural outcomes. However, to date, these studies have not systematically investigated how effective leader behaviours inform justice perceptions, nor has research assessed the joint effects of leadership and justice on social exchange quality and employee outcomes. Therefore, the purpose of this research was twofold. First, we meta-analytically examined the relationships between three types of leader behaviours and four dimensions of justice referenced to the leader and the organization. Second, we investigated the joint effects of leader behaviours and justice perceptions to gain a greater understanding of how these assessments of a leader impact LMX, task performance, and job satisfaction.

With respect to organizational justice research, our results demonstrate that leader behaviours differentially inform justice perceptions. Specifically, we found that task leader behaviours were the most important predictor of leader-focused procedural and leader-focused distributive justice perceptions. These results provide support for the control theory perspective of procedural justice (Thibaut and Walker, 1975, 1978) and the equity theory perspective of distributive justice (Adams, 1965). Conversely, relational leader behaviours were the most important predictor of organization-focused procedural justice, and change leader behaviours were the most important predictor of organization-focused distributive justice. These results are most consistent with the relational models of procedural justice (Lind and Tyler, 1988) and personal determinants perspective of 


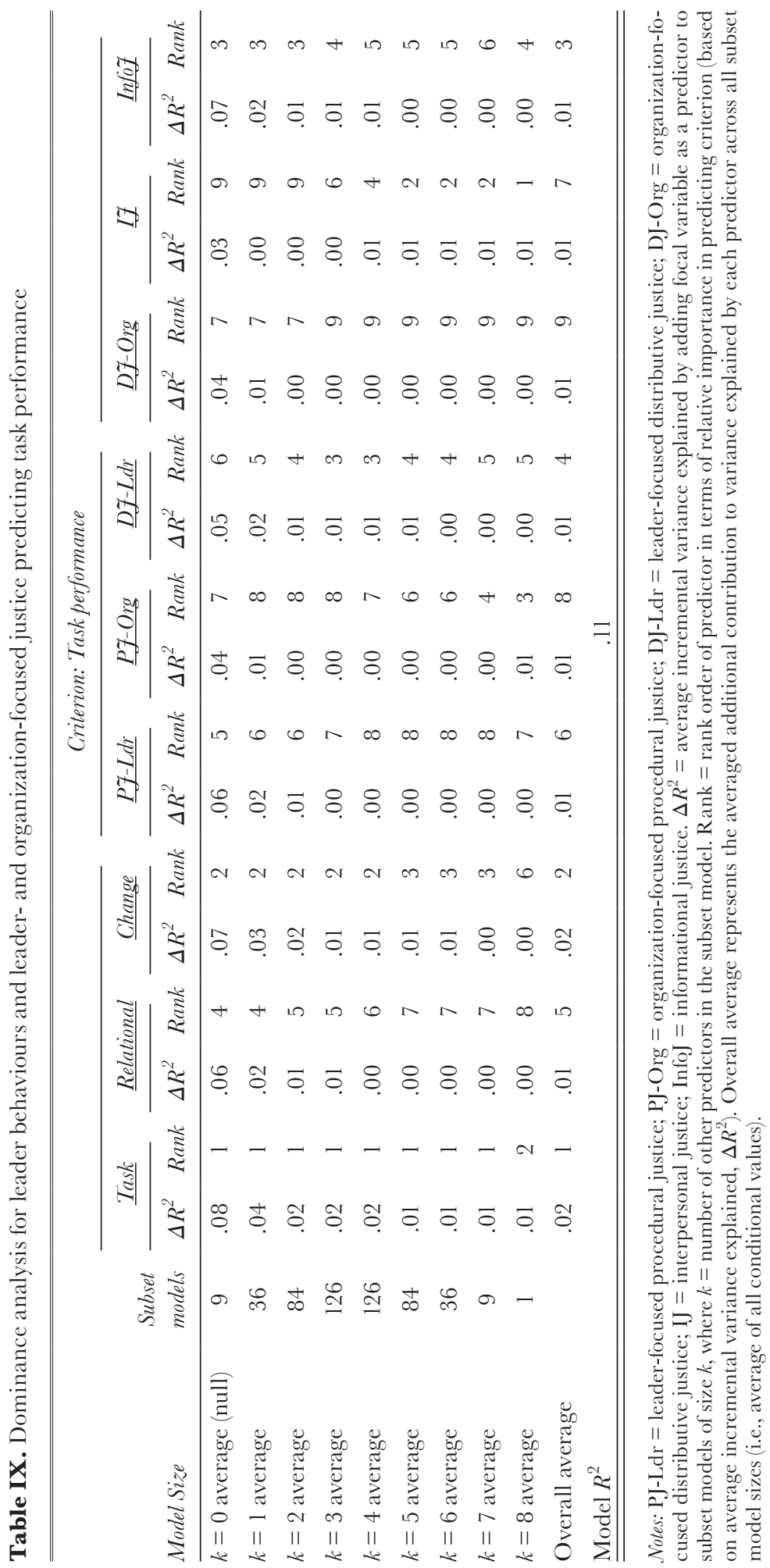




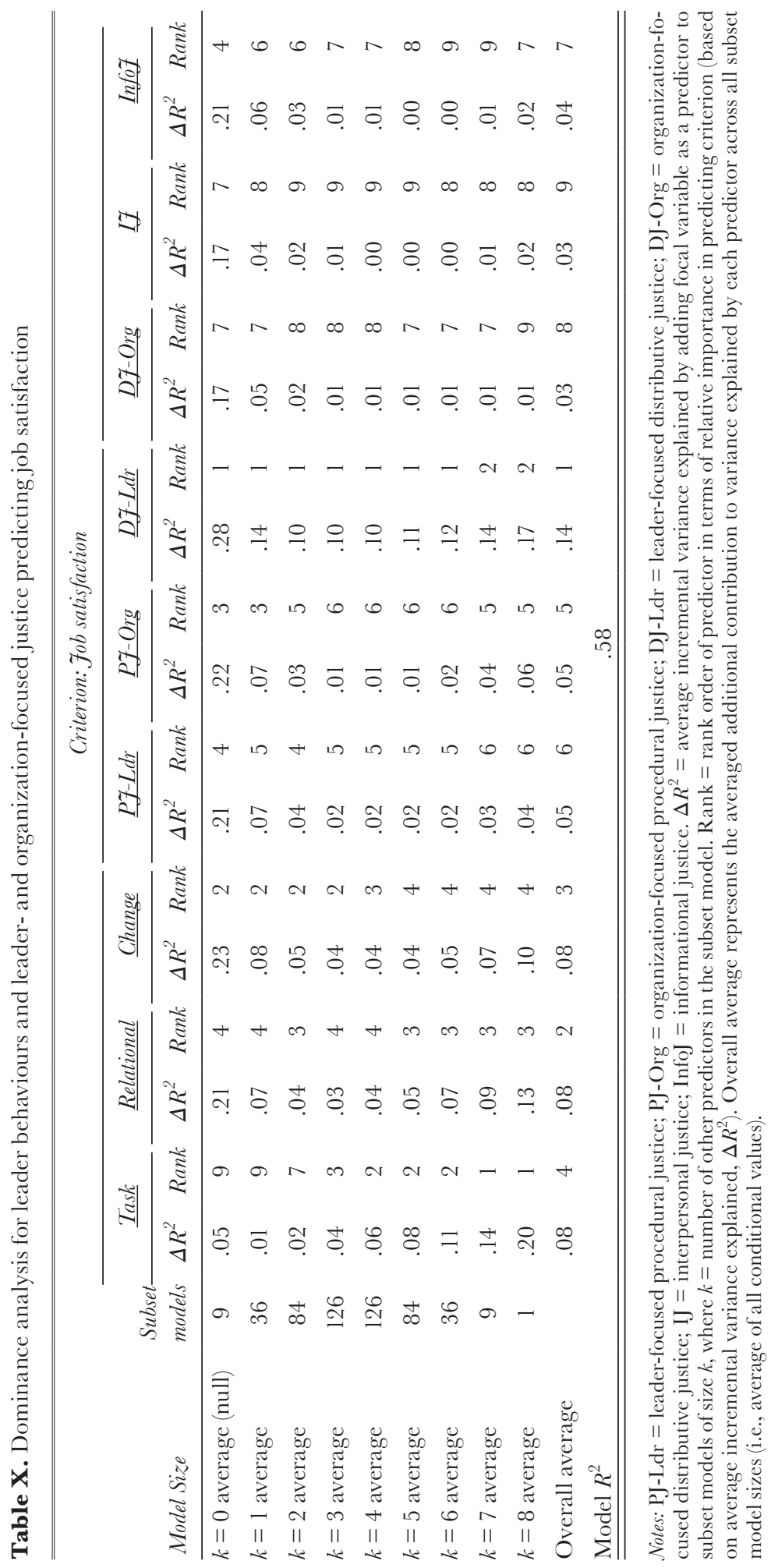

(C) 2018 John Wiley \& Sons Ltd and Society for the Advancement of Management Studies 
Table XI. Summary of results for hypotheses and research questions

Hypothesis/Research Question Result

H1(a): Task leader behaviours will exhibit a stronger positive relationship with Supported leader-focused procedural justice perceptions than change leader behaviours.

$\mathrm{Hl}$ (b): Relational leader behaviours will exhibit a stronger positive relation- Not supported ship with leader-focused procedural justice perceptions than change leader behaviours.

H2(a): Task leader behaviours will exhibit a stronger positive relationship Not supported with organization-focused procedural justice perceptions than change leader behaviours.

H2(b): Relational leader behaviours will exhibit a stronger positive relation- Supported ship with organization-focused procedural justice perceptions than change leader behaviours.

H3(a): Task leader behaviours will exhibit a stronger positive relationship with leader-focused distributive justice perceptions than relational leader behaviours.

H3(b): Change leader behaviours will exhibit a stronger positive relationship Not supported with leader-focused distributive justice perceptions than relational leader behaviours.

H4(a): Task leader behaviours will exhibit a stronger positive relationship with organization-focused distributive justice perceptions than relational leader behaviours.

H4(b): Change leader behaviours will exhibit a stronger positive relationship Supported with organization-focused distributive justice perceptions than relational leader behaviours.

H5(a): Relational leader behaviours will exhibit a stronger positive relationship with interpersonal justice perceptions than task leader behaviours.

H5(b): Relational leader behaviours will exhibit a stronger positive relationship Not supported with interpersonal justice perceptions than will change leader behaviours.

H6(a): Change leader behaviours will exhibit a stronger positive relationship Supported with informational justice perceptions than will either task leader behaviours.

H6(b): Change leader behaviours will exhibit a stronger positive relationship Supported with informational justice perceptions than will relational leader behaviours.

RQ1: When considered simultaneously, what unique contributions do leader behaviours and justice dimensions make to explaining variance in LMX, and what is the relative important of these contributions?

RQ2(a): When considered simultaneously, what unique contributions do leader behaviours and justice dimensions make to explaining variance in task performance, and what is the relative importance of these contributions?

RQ2(b): When considered simultaneously, what unique contributions do leader behaviours and justice dimensions make to explaining variance in job satisfaction, and what is the relative importance of these contributions?

Relational leader behaviours exhibit conditional dominance

Task \& change leader behaviours exhibit general dominance

Leader-focused distributive justice exhibits general dominance

Notes: $\mathrm{H}=$ hypothesis; $\mathrm{RQ}=$ research question. 
distributive justice, which emphasizes the importance of the social and interpersonal aspects of reward allocation decisions (Greenberg, 1993; Levanthal, 1980).

Our hypotheses related to interpersonal and informational justice demonstrate support for the role of change leader behaviours in informing these justice dimensions. That is, change leader behaviours that include an emphasis on learning (intellectual stimulation), communication, and encouraging employees most inform perceptions of interpersonal and informational justice (Yukl, 2012). However, with regard to interpersonal justice, the overall average variance explained between change and relational behaviours was minimal (.16 vs. .15, respectively), suggesting that both forms of leader behaviours are important to informing interpersonal justice perceptions.

Another noteworthy finding of Hypotheses 1-4 was that leader behaviours explain considerably more variance in perceptions of organization-focused procedural and distributive justice than leader-focused procedural and distributive justice. These results provide strong support for the role that leader's play as an embodiment of the organization (Cropanzano et al., 2001; Eisenberger et al., 2010; Levinson, 1965). Further, these results lend support to the actor-focused model of justice rule adherence proposed by Scott et al. (2009). This model suggests that leaders have various levels of discretion in the enactment of justice with the least discretion afforded in distributive justice because of organizational factors (e.g., HR policies or practices) that limit a leader's decision-making ability. Therefore, whereas effective leader behaviours explained considerable variance in all dimensions of justice, they explained the least variance in leader-focused distributive justice, which subordinates may attribute to a lack of discretion in outcome allocation decisions.

The findings related to our research questions on the unique contributions of leader behaviours and justice dimensions to explaining variance in social exchange quality and employee outcomes are nuanced. With regard to social exchange quality, leader behaviours dominate the effects. Specifically, relational leader behaviours most inform perceptions of LMX followed by change and task leader behaviours. This is consistent with the conceptual definition and empirical evidence for LMX (for a review, see Dulebohn et al., 2012). However, the results also provide some support for the target similarity framework in organizational justice research. That is, of the six target-specific justice dimensions examined in the analysis, three of the four leader-focused justice dimensions (interpersonal justice, informational justice, and leader-focused procedural justice), explain, on average, more variance in LMX than the two organization-focused justice dimensions.

The results of the research question related to task performance show that task and change leader behaviours were generally the strongest predictors. However, the average variance explained by all leader behaviours and justice dimensions ranged from .01-.02, suggesting that numerous other decisions and behaviours impact task performance. Here again, the results provide support for the target similarity framework given that all four of the leader-focused justice dimensions explained more average variance in task performance than the two organization-focused justice dimensions.

With regard to job satisfaction, leader-focused distributive justice demonstrated conditional dominance for all but the very largest models, and all three leader behaviour 
categories (i.e., relational, change, and task) demonstrated general dominance over the remaining justice dimensions. This highlights the central role that leader allocation decisions and effective leader behaviours play in overall job satisfaction. Given that job satisfaction is generally considered an organization-directed outcome (Rupp et al., 2014), this finding (along with the pattern of average variance explained by the remaining organization- and leader-focused justice dimensions) is counter to target similarity model predictions. However, it reaffirms the powerful role that leaders play in an employee's experience in the organization (Hui et al., 2004), and it supports the recommendation by Colquitt and colleagues (2013) for scholars to reference all justice dimensions to the leader to better explain variance in outcomes.

\section{Theoretical Implications}

Our results detail several important theoretical contributions. First, we provide evidence that task, relational, and change leader behaviours play a significant role in informing justice perceptions. In fact, the variance explained by leader behaviours in the models examining leader- and organization-focused justice dimensions ranged from .26 to .65, suggesting that employees take into account multiple behaviours of their leader when assessing organizational justice. This shows that research that focuses only on justice decisions likely provides an incomplete assessment of justice perception formation, and future research should incorporate role-relevant leader behaviours into theoretical models of justice perceptions.

The differences in findings between the most important predictors of leader-focused procedural and distributive justice perceptions (task leader behaviours) and organization-focused procedural and distributive justice perceptions (relational and change leader behaviours, respectively) have implications for justice theories as well. Namely, leaders affect perceptions of their own procedural and distributive justice through how they carry out concrete and specific activities, likely because of the proximity and salience of these behaviours (Lind et al., 2001). Conversely, it is the more social behaviours (relational and change) that are informative for representing the organization with regard to justice. Change is inevitable in organizations (Van de Ven and Poole, 1995); we show that effective change leaders can positively influence employee perceptions of organization-focused distributive justice. Further, relational leader behaviours - how effective leaders are at showing consideration and respect to employees - influences whether employees perceive the organization as being procedurally fair.

The conceptual model presented in this study and the results of the research questions provide evidence of the need for greater integration of leadership and justice theories. These two literatures have evolved largely independently without articulating (a) the behaviours of a 'just leader,' and (b) the impact of a 'just leader' on employee outcomes. We demonstrate that 'just leaders' impact outcomes differently than what has been reported in prior meta-analyses that have not taken into account a more holistic view of the leader. For example, the organizational justice meta-analysis by Rupp et al. (2014) presented evidence that the variance explained in LMX by justice perceptions was .51. In our study, the variance explained in LMX by leader behaviours and justice perceptions is .72: the overall average variance explained by the three leader behaviours is .42 , and the overall 
average variance explained by all justice dimensions is .32. This suggests that LMX quality is shaped more by the leader's behaviours than justice perceptions. As a second example, the leader behaviour meta-analysis by DeRue et al. (2011) presented data that the variance explained in job satisfaction by task, relational, and change leader behaviours is .51. In our study, when examining the results for job satisfaction, the variance explained by effective leader behaviours is .24 whereas the overall average variance explained by all justice dimensions is .34 (total Model $R^{2}=.58$ ), suggesting that job satisfaction is more influenced by justice perceptions that effective leadership. Therefore, to more accurately assess the effects of leaders in social exchange relationships on employee outcomes, future research should concurrently consider leader behaviours and justice perceptions.

Finally, the high correlations between leader behaviours and justice dimensions (ranging from .32 to .75$)$ indicate that employees perceive effective leader behaviours as containing elements of justice. Yet remarkably, there are very few explicit references to justice or fairness in either the theoretical work (e.g., Bass, 1985; Conger and Kanungo, 1987; Fleishman, 1953; Pawar and Eastman, 1997) or the most common measures of effective leader behaviours (e.g., Leader Behavior Description Questionnaire, Stodgill, 1963; Multifactor Leadership Questionnaire, Avolio and Bass, 2004). Therefore, future theoretical and empirical work on effective leader behaviours is needed to clearly articulate and measure the fairness elements of effective task, relational, and change leader behaviours. As a starting point, task leadership research should explicitly articulate the importance of fairness in transactional and contingent reward behaviours such as fairly solving problems and rewarding employee performance equitably. Similarly, relational leadership research should emphasize the fairness aspects of providing support and showing consideration, and change leadership research should emphasize the fair and just communication aspects of a transformational or charismatic leader.

\section{Suggestions for Future Research}

Humphrey (2011) emphasized the importance of advancing the literature through reviews. Therefore, we would like to suggest several opportunities for future research. First, future research on leadership and justice should consider alternate study design and measurement options. Most of the studies in our meta-analysis used the same source of data for measuring leader behaviour and justice variables and/or measured these variables at the same time. Therefore, there could be a 'halo effect' affecting the ratings of leadership and justice, and it would be beneficial to disentangle leader behaviours from justice perceptions through measurement that clearly delineates the two. This could be done by examining the collective (i.e., bystander) effects of justice and the contextual factors that may influence these perceptions; by separating measurement in time; or by developing multilevel models to explore the effects of executive leadership and justice behaviours on lower level employees.

Next, future research should examine moral leader behaviours (e.g., ethical, authentic, moral leadership - see Dinh et al., 2014 for a review) and justice dimensions, and their joint effects on performance outcomes. Given the connection between ethics-related judgments and organizational justice perceptions, these behaviours may have significant implications for justice perceptions. 
Also, Rupp and Aguino (2009) have suggested that leadership development programs should include justice as a leadership competency, and we are aware of no research to date to assess these types of programs. The results of our study suggest that leader behaviours and justice dimensions have diverse impacts on outcomes. Therefore, leadership development programs should take into account a broader range of behavioural competencies - including fairness - to have a greater impact on employee outcomes.

The primary studies in our sample were largely cross-sectional, so there is a need for future research to examine how perceptions of leadership and justice develop over time. Holtz and Harold (2009) have conducted preliminary research in this area and their results demonstrated that leader-focused justice perceptions do change over time. However, we know little about how leader behaviours inform justice perceptions as the social exchange relationship develops, stabilizes, and changes.

\section{Limitations}

This study has a number of limitations. First, given that the meta-analyses relied on primary studies as the source of data for analysis, our conclusions are also limited by the limitations in the primary studies. As mentioned above, much of the data measuring leader behaviours and justice dimensions in our study was collected at the same time from the same source. Therefore, the estimated meta-analytic relationships could be inflated due to common method bias (Podsakoff et al., 2006). In addition, the average number of studies $(k)$ for the correlations between leader behaviours and justice variables is 8.5 (range: 3-23) which is somewhat small relative to the number of independent samples in other leadership and justice meta-analyses.

Also, we utilized DA to test the hypotheses because it is a superior statistical method to other types of analyses when assessing the relative importance of correlated predictor variables. However, the interpretation of $\mathrm{DA}$ is a qualitative comparison of the relative importance of predictors across model sizes (Budescu, 1993). Therefore, when there are small differences in the average $\Delta R^{2}$ between predictors, the conclusions for these hypotheses should be interpreted with caution (e.g., Hypothesis $1 \mathrm{~b}$ found an average $\Delta R^{2}$ of .15 vs. .14 for change and relational leader behaviours, respectively, in predicting leader-focused procedural justice).

Furthermore, we were only able to examine a limited number of criterion variables due to the availability of primary data, and consequently we were not able to examine the links between leader behaviours, justice perceptions, and other outcomes such as organizational citizenship behaviours and counterproductive work behaviours. Thus, there is a need and opportunity for scholars to expand research efforts to consider a broader set of employee outcomes.

\section{GONGLUSION}

There has been considerable empirical research into leader behaviours and leader- and organization-focused justice perceptions (Colquitt et al., 2013; DeRue et al., 2011; Rupp 
et al., 2014). However, existing research has yet to assess how effective leader behaviours impact these perceptions of fairness. To address this gap, we meta-analysed the relationships between three types of leader behaviours and four dimensions of justice referenced to the leader and the organization in an attempt to provide greater focus on the 'face' of organizational justice. Our results demonstrate that task, relational, and change leader behaviours differentially impact perceptions of procedural, distributive, interpersonal, and informational justice. Further, we found that leader behaviours and justice dimensions have unique effects on employee outcomes when considered jointly. We hope that future research can utilize these findings as a platform for additional empirical and theoretical advancements in leadership and organizational justice research.

\section{AGKNOWLEDGMENT}

The authors would like to acknowledge and thank Fred Oswald for his helpful guidance on the meta-analytic methods and analyses in the manuscript. We are also grateful to Jim Combs and two anonymous reviewers for their thoughtful comments and efforts toward improving the manuscript.

\section{NOTES}

[1] Our data included one study where interpersonal justice and informational justice were referenced to the organization (i.e., all other studies referenced the leader for these dimensions). This was not surprising given that original theorizing on interpersonal and informational justice suggested these dimensions are social determinants of fairness attributable to a specific source (Greenberg, 1977). Therefore, we do not offer predictions regarding organization-focused interpersonal justice nor organization-focused informational justice.

[2] Yukl (2012) actually presents four meta-categories: task, relational, change, and external leadership behaviours. External leadership behaviours include networking, external monitoring, and representing the organization to stakeholders outside of the organization. Given that these behaviours are targeted to non-subordinate employees, they are outside the scope of this study and are not included in our discussion.

[3] Supplementary materials with additional coding information, including construct coding definitions and a summary of data included in the meta-analysis (i.e., sample size, correlations, reliabilities, variables, and variable scales) can be found online at the fournal of Management Studies website.

[4] Consistent with prior meta-analytic research (Colquitt et al., 2011; Rupp et al., 2009), we coded the following social exchange quality variables noting the target of the exchange quality as well: affective commitment (leader-directed, organization-directed); LMX (leader-directed); perceived support (leader-directed, organization-directed); and trust (leader-directed, organization-directed). In addition, we coded the following affective and behavioural outcome variables noting the target: satisfaction (leader-directed); global job satisfaction (organization-directed); identification (leader-directed, organization-directed); counterproductive work behaviours (leader-directed, organization-directed); organizational citizenship behaviours (leader-directed, organization-directed); and task performance (leader-directed). Given the limited data available from primary studies, only LMX, task performance (leader-directed), and global job satisfaction (organization-directed) were used in the analyses.

[5] We are not aware of any published meta-analytic estimates for the correlations among referent-specific justice variables. Therefore, in response to a comment from the Associate Editor and an anonymous reviewer, we supplemented our original coding by searching the reference section of the 
most recent multifoci justice meta-analysis that presents data for the four dimensions of organizational justice (i.e., Colquitt et al., 2011) for studies included in their meta-analysis from the Financial Times 50 journal list. As a result of the search, 84 additional studies (95 independent samples) were coded and added to our dataset. Additional details for this coding are available from the first author.

\section{REFERENGES}

Adams, J. S. (1965). 'Inequity in social exchange'. In Berkowitz, B. (Ed.), Advances in Experimental Social Psychology, 2. New York: Academic Press, 267-99.

Ambrose, M. L. and Arnaud, A. (2005). 'Are procedural justice and distributive justice conceptually distinct?'. In Greenberg, J. and Colquitt, J. A. (Eds), Handbook of Organizational Fustice. Mahwah, NJ: Lawrence Erlbaum Associates, 59-84.

Avolio, B. J. and Bass, B. M. (2004). Multifactor Leadership Questionnaire, 3rd edition. Palo Alto, CA: Mind Garden.

Azen, R. and Budescu, D. V. (2003). 'The dominance analysis approach for comparing predictors in multiple regression'. Psychological Methods, $8,129-48$.

Bass, B. M. (1985). Leadership and Performance Beyond Expectations. New York: Free Press.

Bass, B. M. (2008). The Bass Handbook of Leadership, 4th edition. New York: Free Press.

Bass, B. M. (1990). 'From transactional to transformational leadership: Learning to share the vision'. Organizational Dynamics, 18, 19-31.

Bentler, P. M. and Raykov, T. (2000). 'On measures of explained variance in nonrecursive structural equation models'. Fournal of Applied Psychology, 85, 125-31.

Blader, S. L. and Tyler, T. R. (2015). 'Relational models of procedural justice'. In Cropanzano, R. and Ambrose, M. (Eds), The Oxford Handbook of Justice in the Workplace. New York: Oxford University Press, 351-70.

Blau, P. M. (1964). Exchange and Power in Social Life. New Brunswick, NJ: Transaction Publishers.

Borman, W. C. and Brush, D. H. (1993). 'More progress toward a taxonomy of managerial performance requirements'. Human Performance, 6, 1-21.

Brower, H. H., Schoorman, F. D. and Tan, H. H. (2000). 'A model of relational leadership: The integration of trust and leader-member exchange'. The Leadership Quarterly, 11, 227-50.

Budescu, D. V. (1993). 'Dominance analysis: A new approach to the problem of relative importance of predictors in multiple regression'. Psychological Bulletin, 114, 542-51.

Burns, J. M. (1978). Leadership. New York: Harper \& Row.

Cascio, W. F. and Aguinis, H. (2008). 'Research in industrial and organizational psychology from 19632007: Changes, choices, and trends'. Fournal of Applied Psychology, 93, 1062-81.

Colquitt, J. A. (2001). 'On the dimensionality of organizational justice: A construct validation of a measure'. Fournal of Applied Psychology, 86, 386-400.

Colquitt, J. A. (2008). 'Two decades of organizational justice: Findings, controversies, and future directions'. In Cooper, C. L. and Barling, J. (Eds), Sage Handbook of Organizational Behavior. Newbury Park, CA: Sage, 73-88.

Colquitt, J. A., Scott, B. A., Rodell, J. B., Long, D. M., Zapata, C. P., Conlon, D. E. and Wesson, M. J. (2013). 'Justice at the millennium, a decade later: A meta-analytic test of social exchange and affect-based perspectives'. Fournal of Applied Psychology, 98, 199-236.

Combs, J. G., Ketchen Jr., D. J., Crook, R. T. and Roth, P. L. (2011). 'Assessing cumulative evidence within "macro" research: Why meta-analysis should be preferred over vote counting'. Fournal of Management Studies, 48, 178-97.

Conger, J. A. (1989). 'Leadership: The art of empowering others'. Academy of Management Executive, 3, 17-24.

Conger, J. A. and Kanungo, R. N. (1987). 'Toward a behavioral theory of charismatic leadership in organizational settings'. Academy of Management Review, 12, 637-47.

Cropanzano, R., Byrne, Z. S., Bobocel, D. R. and Rupp, D. E. (2001). 'Moral virtues, fairness heuristics, social entities, and other denizens of organizational justice'. Fournal of Vocational Behavior, 58, 164-209.

Cropanzano, R. and Mitchell, M. S. (2005). 'Social exchange theory: An interdisciplinary review'. Fournal of Management, 31, 874-900.

Cropanzano, R., Prehar, C. A. and Chen, P. Y. (2002). 'Using social exchange theory to distinguish procedural from interactional justice'. Group \& Organization Management, 27, 324-51. 
De Cremer, D., van Dijke, M. and Bos, A. E. R. (2007). 'When leaders are seen as transformational: The effects of organizational justice'. Fournal of Applied Social Psychology, 37, 1797-816.

DeRue, D. S., Nahrgang, J. D., Wellman, N. E. D. and Humphrey, S. E. (2011). 'Trait and behavioral theories of leadership: An integration and meta-analytic test of their relative validity'. Personnel Psychology, 64, 7-52.

Dierdorff, E. C., Rubin, R. S. and Morgeson, F. P. (2009). 'The milieu of managerial work: an integrative framework linking work context to role requirements'. Fournal of Applied Psychology, 94, 972-88.

Dinh, J. E., Lord, R. G., Gardner, W. L., Meuser, J. D., Liden, R. C. and Hu, J. (2014). 'Leadership theory and research in the new millennium: Current theoretical trends and changing perspectives'. The Leadership Quarterly, 25, 36-62.

Duval, S. and Tweedie, R. (2000). 'A nonparametric "Trim and Fill" method of accounting for publication bias in meta-analysis'. Fournal of the American Statistical Association, 95, 89-98.

Dulebohn, J. H., Bommer, W. H., Liden, R. C., Brouer, R. L. and Ferris, G. R. (2012). 'A meta-analysis of antecedents and consequences of leader-member exchange: Integrating the past with an eye toward the future'. Fournal of Management, 38, 1715-59.

Eisenberger, R., Karagonlar, G., Stinglhamber, F., Neves, P., Becker, T. E., Gonzalez-Morales, M. G. and Steiger-Mueller, M. (2010). 'Leader-member exchange and affective organizational commitment: The contribution of supervisor's organizational embodiment'. Fournal of Applied Psychology, 95, 1085-103.

Eisenberger, R., Stinglhamber, F., Vandenberghe, G., Sucharski, I. L. and Rhoades, L. (2002). 'Perceived supervisor support: contributions to perceived organizational support and employee retention'. Fournal of Applied Psychology, 87, 565-73.

Fleishman, E. A. (1953). 'The description of supervisory behavior'. Fournal of Applied Psychology, 37, 1-6.

Frazier, M. L., Johnson, P. D., Gavin, M., Gooty, J. and Snow, D. B. (2010). 'Organizational justice, trustworthiness, and trust: A multifoci examination'. Group \& Organization Management, 35, 39-76.

Gardner, W. L., Lowe, K. B., Moss, T. W., Mahoney, K. T. and Cogliser, C. C. (2010). 'Scholarly leadership of the study of leadership: A review of The Leadership Quarterly's second decade, 2000-2009'. The Leadership Quarterly, 21, 922-58.

Gottfredson, R. K. and Aguinis, H. (2016). 'Leadership behaviors and follower performance: Deductive and inductive examination of theoretical rationales and underlying mechanisms'. Fournal of Organizational Behavior, 38, 558-91.

Gouldner, A. W. (1960). 'The norm of reciprocity: A preliminary statement'. American Sociological Revierw, 25, 161-78.

Graen, G. B. and Scandura, T. A. (1987). 'Toward a psychology of dyadic organizing'. Research in Organizational Behavior, 9, 175-208.

Greenberg, J. (1993). 'The social side of fairness: Interpersonal and informational classes of organizational justice'. In Cropanzano, R. (Ed.), Fustice in the Workplace: Approaching Fairness in Human Resource Management. Hillsdale, NJ: Lawrence Erlbaum Associates, 79-103.

Greenleaf, R. K. (1977). Servant Leadership: A Fourney into the Nature of Legitimate Power and Greatness. New York: Paulist Press.

Holtz, B. C. and Harold, C. M. (2009). 'Fair today, fair tomorrow? A longitudinal investigation of overall justice perceptions'. Fournal of Applied Psychology, 94, 1185-99.

Holtz, B. C. and Harold, C. M. (2013). 'Effects of leadership consideration and structure on employee perceptions of justice and counterproductive work behavior'. Fournal of Organizational Behavior, 34, 492-519.

Howell, J. M. and Avolio, B. J. (1993). 'Transformational leadership, transactional leadership, locus of control, and support for innovation: Key predictors of consolidated-business-unit performance'. Fournal of Applied Psychology, 78, 891-902.

Hui, C., Lee, C. and Rousseau, D. M. (2004). 'Employment relationships in China: Do workers related to the organization or to people'. Organization Science, 15, 232-40.

Hulin, G. L. and Judge, T. A. (2003). 'Job attitudes'. In Borman, W. G., Ilgen, D. R. and Klimoski, R. J. (Eds), Handbook of Psychology: Industrial and Organizational Psychology. Hoboken, NJ: John Wiley \& Sons, $255-76$.

Humphrey, S. E. (2011). 'What does a great meta-analysis look like?'. Organizational Psychology Reviewe, 1, 99-103.

Hunter, J. E. and Schmidt, F. L. (2004). Methods of Meta-analysis: Correcting Error and Bias in Research Findings, 2nd edition. Thousand Oaks, CA: Sage. 
Johnson, J. W. (2000). 'A heuristic method for estimating the relative weight of predictor variables in multiple regression'. Multivariate Behavioral Research, 35, 1-19.

Judge, T. A., Piccolo, R. E. and Ilies, R. (2004). 'The forgotten ones? The validity of consideration and initiating structure in leadership research'. Fournal of Applied Psychology, 89, 36-51.

Judge, T. A., Thoresen, G. J., Bono, J. E. and Patton, G. K. (2001). 'The job satisfaction-job performance relationship: A qualitative and quantitative review'. Psychological Bulletin, 127, 376-407.

Kahai, S. S., Sosik, J. J. and Avolio, B. J. (1997). 'Effects of leadership style and problem structure on work group process and outcomes in an electronic meeting system environment'. Personnel Psychology, 50, $121-46$.

Kepes, S., McDaniel, M. A., Brannick, M. T. and Banks, G. C. (2013). 'Meta-analytic reviews in the organizational sciences: Two meta-analytic schools on the way to MARS (the Meta-Analytic Reporting Standards)'. Fournal of Business and Psychology, 28, 123-43.

Kirkman, B. L., Chen, G., Farh, J.-L., Chen, Z. X. and Lowe, K. B. (2009). 'Individual power distance orientation and follower reactions to transformational leaders: A cross-level, cross-cultural examination'. Academy of Management Fournal, 52, 744-64.

Lavelle, J. J., McMahan, G. C. and Harris, G. M. (2009). 'Fairness in human resource management, social exchange relationships, and citizenship behavior: Testing linkages of the target similarity model among nurses in the United States'. International Journal of Human Resource Management, 20, 2419-34.

Lavelle, J. J., Rupp, D. E. and Brockner, J. (2007). 'Taking a multifoci approach to the study of justice, social exchange, and citizenship behavior: The target similarity model'. Fournal of Management, 33, 841-66.

Levanthal, G. S. (1980). 'What should be done with equity theory? New approaches to the study of fairness in social relationships'. In Gergen, K. J., Greenberg, M. S. and Willis, R. H. (Eds), Social Exchange: Advances in Theory and Research. New York: Plenum Press, 27-55.

Levinson, H. (1965). 'Reciprocation: The relationship between man and organization'. Administrative Science Quarterly, 9, 370-90.

Liao, H. and Rupp, D. E. (2005). 'The impact of justice climate and justice orientation on work outcomes: A cross-level multifoci framework'. Fournal of Applied Psychology, 90, 242-56.

Liden, R. C. and Maslyn, J. M. (1998). 'Multidimensionality of leader-member exchange: An empirical assessment through scale development'. Fournal of Management, 24, 43-72.

Lind, E. A. (2001). 'Fairness heuristic theory: Justice judgments as pivotal cognitions in organizational relations'. In Greenberg, J. (Ed.), Advances in Organizational fustice. Stanford, CA: Stanford University Press, 56-88.

Lind, E. A., Kanfer, R. and Earley, P. C. (1990). 'Voice, control, and procedural justice: Instrumental and noninstrumental concerns in fairness judgments'. Fournal of Personality and Social Psychology, 59, 952-59.

Lind, E. A., Kray, L. and Thompson, L. (2001). 'Primacy effects in justice judgments: Testing predictions from fairness heuristic theory'. Organizational Behavior and Human Decision Processes, 85, 189-210.

Lind, E. A. and Tyler, T. R. (1988). The Social Psychology of Procedural Fustice. New York: Plenum Press.

Masterson, S. S. and Lensges, M. (2015). 'Leader-member exchange and justice'. In Bauer, T. N. and Erdogan, B. (Eds), The Oxford Handbook of Leader-Member Exchange. Oxford: Oxford University Press, 67-84.

Martin, R., Guillaume, Y., Thomas, G., Lee, A. and Epitropaki, O. (2016). 'Leader-member exchange (LMX) and performance: A meta-analytic review'. Personnel Psychology, 69, 67-121.

Mintzberg, H. (1973). The Nature of Managerial Work. New York: Harper \& Row.

Mitchell, M. S., Cropanzano, R. S. and Quisenberry, D. M. (2012). 'Social exchange theory, exchange resources, and interpersonal relationships: A modest resolution of theoretical difficulties'. In Tornblom, K. and Kazemi, A. (Eds), Handbook of Social Resource Theory. New York: Springer, 99-118.

Ng, T. W. (2017). 'Transformational leadership and performance outcomes: Analyses of multiple mediation pathways'. The Leadership Quarterly, 28, 385-417.

Nimon, K. and Oswald, F. L. (2013). 'Understanding the results of multiple linear regression: Beyond standardized regression coefficients'. Organizational Research Methods, 16, 650-74.

Pawar, B. S. and Eastman, K. K. (1997). 'The nature and implications of contextual influences on transformational leadership: A conceptual review'. Academy of Management Review, 22, 80-109.

Podsakoff, P. M., Bommer, W. H., Podsakoff, N. P. and MacKenzie, S. B. (2006). 'Relationships between leader reward and punishment behavior and subordinate attitudes, perceptions, and behaviors: A meta-analytic review of existing and new research'. Organizational Behavior and Human Decision Processes, 99, $113-42$. 
Rotundo, M. and Sackett, P. R. (2002). 'The relative importance of task, citizenship, and counterproductive performance to global ratings of job performance: A policy-capturing approach'. Fournal of Applied Psychology, 87, 66-80.

Rupp, D. E. and Aquino, K. F. (2009). 'Nothing so practical as a good justice theory'. Industrial and Organizational Psychology, 2, 205-10.

Rupp, D. E. and Cropanzano, R. (2002). 'The mediating effects of social exchange relationships in predicting workplace outcomes from multifoci organizational justice'. Organizational Behavior and Human Decision Processes, 89, 925-46.

Rupp, D. E., Shao, R., Jones, K. S. and Liao, H. (2014). 'The utility of a multifoci approach to the study of organizational justice: A meta-analytic investigation into the consideration of normative rules, moral accountability, bandwidth-fidelity, and social exchange'. Organizational Behavior and Human Decision Processes, 123, 159-85.

Scott, B. A., Colquitt, J. A. and Paddock, E. L. (2009). 'An actor-focused model of justice rule adherence and violation: The role of managerial motives and discretion'. Fournal of Applied Psychology, 94, 756-69.

Spreitzer, G. (2007). 'Giving peace a chance: Organizational leadership, empowerment, and peace'. Fournal of Organizational Behavior, 28, 1077-95.

Steichen, T. J. (2000). 'Updates of tests for publication bias in meta-analysis'. Stata Technical Bulletin, 57, 4.

Stinglhamber, F., Marique, G., Caesens, G., Hanin, D. and De Zanet, F. (2015). 'The influence of transformational leadership on followers' affective commitment: The role of perceived organizational support and supervisor's organizational embodiment'. Career Development International, 20, 583-603.

Stodgill, R. M. (1963). Manual for the Leader Behavior Description Questionnaire - Form XII. Columbus, OH: Ohio State University, Bureau of Business Research.

Tett, R. P., Guterman, H. A., Bleier, A. and Murphy, P. J. (2000). 'Development and content validation of a "hyperdimensional" taxonomy of managerial competence'. Human Performance, 13, 205-51.

Thibaut, J. and Walker, L. (1975). Procedural Fustice: A Psychological Analysis. Hillsdale, NJ: Lawrence Erlbaum Associates.

Thibaut, J. and Walker, L. (1978). 'A theory of procedure'. California Law Review, 66, 541-66.

Tyler, T. R. (1989). 'The psychology of procedural justice: A test of the group-value model'. Fournal of Personality and Social Psychology, 57, 830-38.

Tyler, T. R. and Blader, S. L. (2000). Cooperation in Groups: Procedural Fustice, Social Identity, and Behavioral Engagement. New York: Psychology Press.

Tyler, T. R. and Lind, E. A. (1992). 'A relational model of authority in groups'. Advances in Experimental Social Psychology, 25, 115-91.

Van de Ven, A. H. and Poole, M. S. (1995). 'Explaining development and change in organizations'. Academy of Management Review, 20, 510-40.

Wayne, S. J., Shore, L. M., Bommer, W. H. and Tetrick, L. E. (2002). 'The role of fair treatment and rewards in perceptions of organizational support and leader-member exchange'. Fournal of Applied Psychology, 87, 590-98.

Wofford, J. C. and Liska, L. Z. (1993). 'Path-goal theories of leadership: A meta-analysis'. Fournal of Management, 19, 857-876.

Yukl, G. (2012). 'Effective leadership behavior: What we know and what questions need more attention'. Academy of Management Perspectives, 26, 66-85.

Yukl, G., Gordon, A. and Taber, T. (2002). 'A hierarchical taxonomy of leadership behavior: Integrating a half century of behavior research'. Fournal of Leadership \& Organizational Studies, 9, 15-32.

Zhang, Y., LePine, J. A., Buckman, B. R. and Wei, F. (2014). 'It's not fair... or is it? The role of justice and leadership in explaining work stressor-job performance relationships'. Academy of Management Fournal, 57, 675-97.

\section{SUPPORTING INFORMATION}

Additional supporting information may be found online in the Supporting Information section at the end of the article. 